\title{
ABSTRACT \\ THE EFFECT OF SONGS WITH VIOLENT LYRICS ON INTERPERSONAL AGGRESSION
}

\author{
By Grant M. Heller
}

The focus of this study was to investigate the relation between listening to music containing violent lyrics and interpersonal aggression. To examine this relation, participants wrote a brief essay and then received feedback from a second ostensible participant as part of a study on peer feedback and writing. Participants were assigned randomly to receive either positive or negative feedback from the other and were then provided an opportunity to evaluate an essay written by the other. Prior to receiving the feedback, participants were assigned randomly to listen to a song with either violent lyrics or non-violent lyrics.

Consistent with previous research, those receiving provocative negative feedback reported more negative affect and evaluated the second participant's essay more negatively than those who received positive feedback. However, despite finding a difference in perceived aggressive content between violent and non-violent songs, exposure to violent songs had no discernable effect on interpersonal aggression. The results provide mixed support for predictions made using the General Aggression Model (GAM). 
THE EFFECT OF SONGS WITH VIOLENT LYRICS ON INTERPERSONAL AGGRESSION

by

Grant M. Heller

A Thesis Submitted

In Partial Fulfillment of the Requirements

For the Degree of

Master of Science-Psychology

Plan of Study Experimental

at

The University of Wisconsin Oshkosh

Oshkosh WI 54901-8621

May 2009
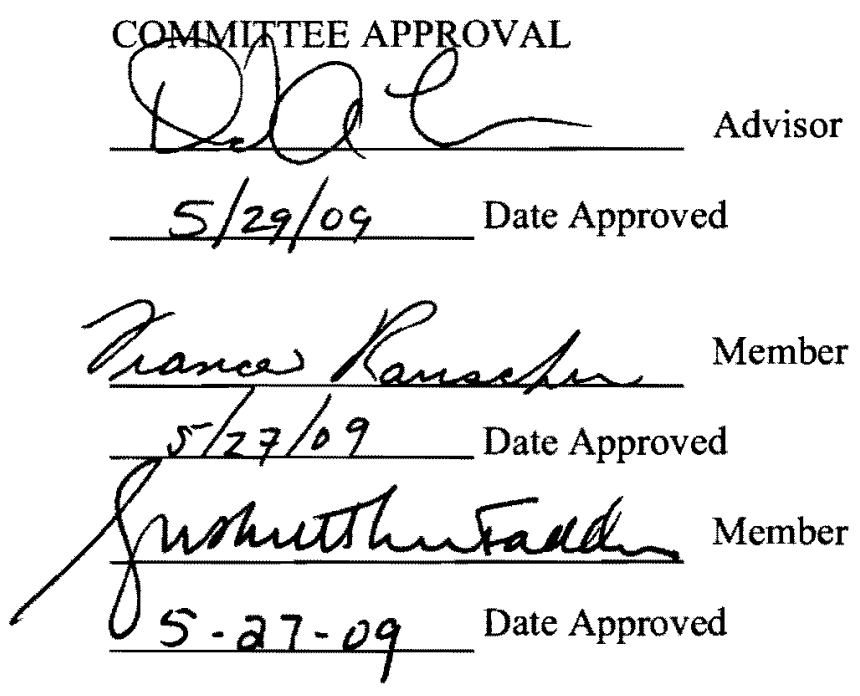

INTERIM PROVOST

AND VICE CHANCELLOR

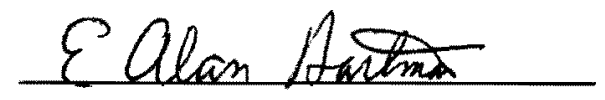

$7 / 8 / 2005$

Date Approved

FORMAT APPROVAL

$\frac{\text { Shares folttiendev }}{6 / 1 / 2009}$

Date Approved 
For Sylvie: My best friend, my love, and my inspiration. Thank you for always believing in me. 


\section{ACKNOWLEDGEMENTS}

I am greatly indebted to the members of my thesis committee for their time, support, and guidance. Thank you Dr. David Lishner for serving as chairperson for my committee; I am grateful for your insightful coaching and counsel, as well as your abundant patience with me throughout this lengthy process. Thank you to Dr. Frances Rauscher for your willingness to serve as a mentor for me, and for fostering my excitement with psychological research in the first place. Thank you to Dr. Susan McFadden for providing your clarity and wisdom, as well as your expertise in the area of emotion.

I also wish to thank Justin Fowler for devoting countless hours to mastering the experimental procedure involved with this study and in assisting with data collection. Thank you to Carla Eichinger for acting as the voice of Samantha Becket. Thank you also to my parents for all of your help and support. Finally, I wish to thank all my other friends, fellow students, and teachers in the University of Wisconsin Oshkosh Psychology Department. 


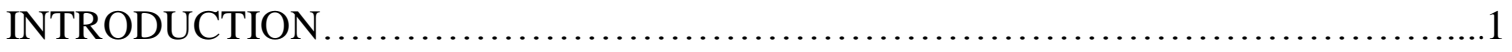

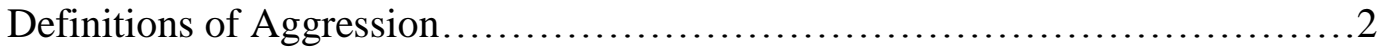

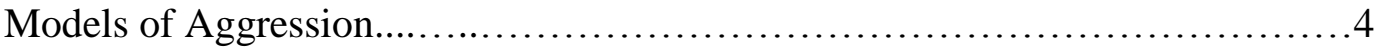

Frustration-Aggression Model and Cognitive Neoassociation Theory.......4

Social Learning Theory ............................................. 6

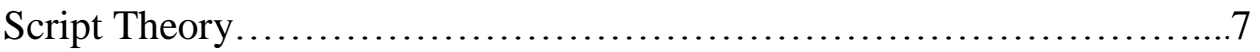

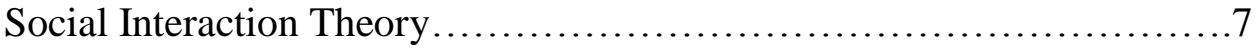

Excitation Transfer................................................ 8

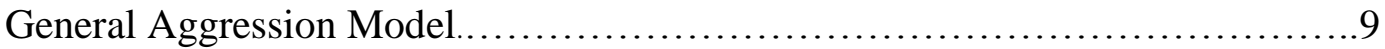

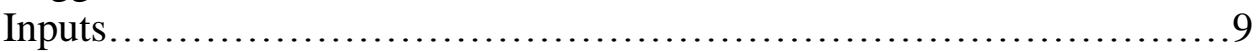

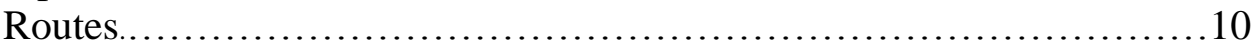

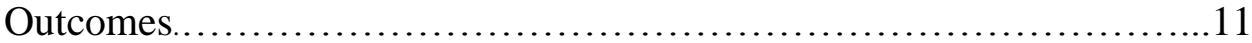

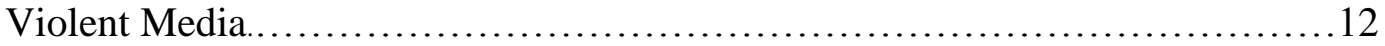

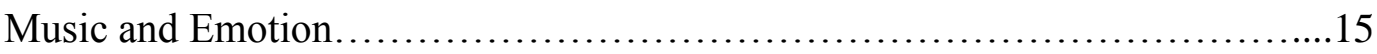

Present Research.....................................................

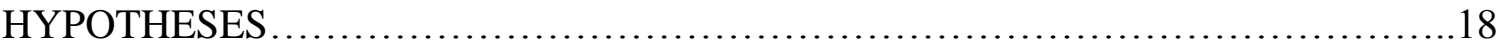

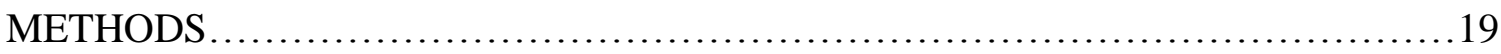

Participants............................................................. 19

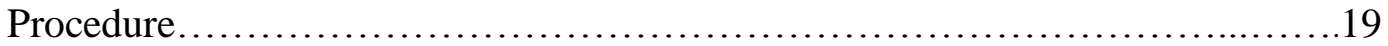

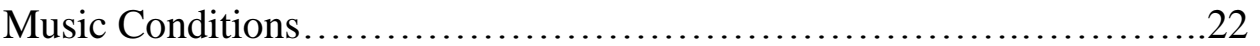

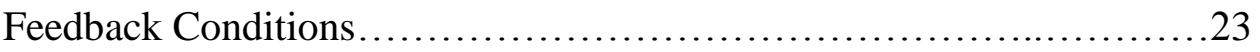

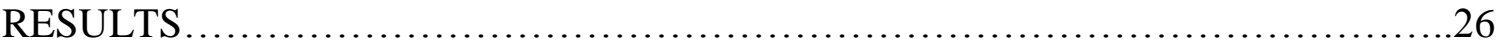

Inputs: Ratings of Violence...................................................26

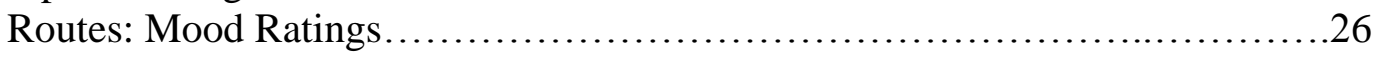

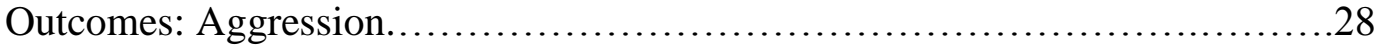


TABLE OF CONTENTS (Continued)

Page

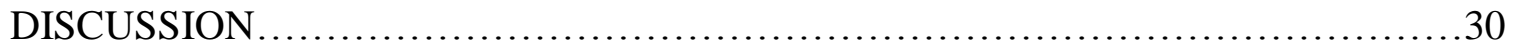

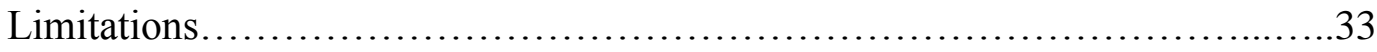

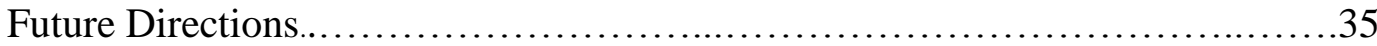

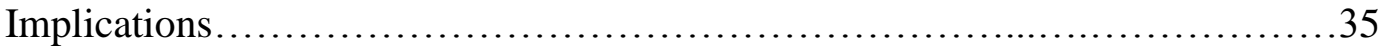

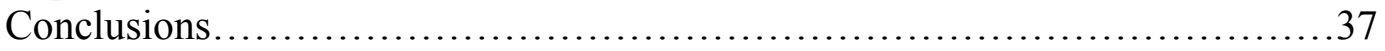

\section{APPENDIXES}

Appendix A: Peer Review Study Informed Consent...........................38

Appendix B: Peer Review Study Instructions...............................40

Appendix C: Essay Task................................................42

Appendix D: Music Pilot Study Informed Consent.............................44

Appendix E: Music Pilot Study Instructions...................................46

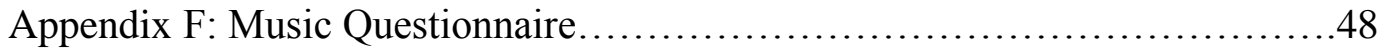

Appendix G: Audio Instructions.............................................51

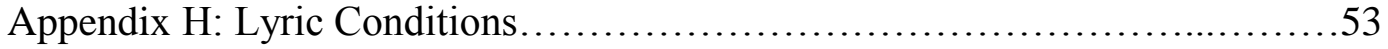

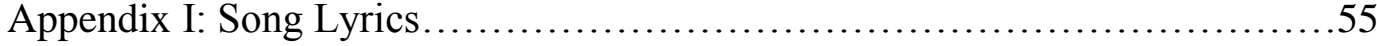

Appendix J: Feedback Form...............................................64

Appendix K: Essay in Female Handwriting....................................66

Appendix L: Essay in Male Handwriting.....................................68

Appendix M: Positive Feedback in Female Handwriting..........................70

Appendix N: Insulting Negative Feedback in Female Handwriting................72

Appendix O: Positive Feedback in Male Handwriting............................ 74

Appendix P: Insulting Negative Feedback in Male Handwriting..................76

Appendix Q: Quality of Feedback Questionnaire.............................78

Appendix R: Tables.............................................................

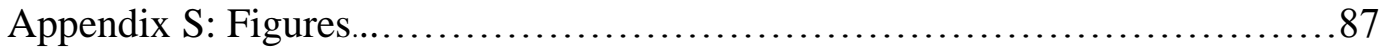

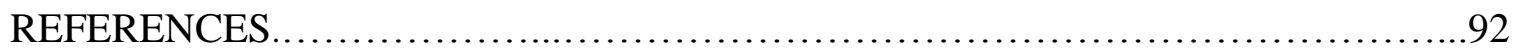


I put a hole in a nigga for fucking with me

My back on the wall, now you gonna see

Better watch how you talk, when you talk about me

'Cause I'll come and take your life away

- 50 Cent, “Many Men” (2003a)

\section{INTRODUCTION}

A large body of research suggests that exposure to violent media increases accessibility to aggressive cognitions and the expression of aggressive behavior (Anderson et al., 2003). Studies investigating the consequences of exposure to violent media span five decades, and include numerous experiments, a meta-analysis (Paik \& Comstock, 1994), and a major longitudinal study (Huesmann, Moise-Titus, Podolski, \& Eron, 2003). In addition to television programs and movies, this research has broadened its scope through the years to examine the effects of violent video games, pornography, music videos, and music on aggressive cognition and behavior. Overall, findings largely support the hypothesis of a positive association between exposure to violent media and subsequent aggressive behavior (e.g., American Psychological Association, 1993; Center for Disease Control, 1991; Joint Statement, 2001; National Academy of Science, 1993; National Institute of Mental Health, 1982; National Television Violence Study, 1996; Surgeon General, 1972). The implications of this association have been compelling enough to spur debates concerning first amendment rights as to whether the government should restrict access to media violence (e.g., Leone, Szumski, Stalcup, Barbour, \& Dudley, 1999; "Violence Bill Debated in Washington," 1990). 
The focus of this study was to investigate the relation between listening to music containing violent lyrics and interpersonal aggression. Interest in the influence of music on personality and behavior goes back to the ancient Greeks. Discussion of the use of music for the edification of moral character can be found in Aristotle's Politics and Plato's Laws (Grout \& Palisca, 2001). In fact, Plato even warned that, “Any musical innovation is full of danger to the whole state, and ought to be prohibited" (cited in Fox \& Williams, 1974, p. 352). Yet, in comparison to other forms of media, relatively little research has been conducted solely on music without accompanying video content. Of these studies, few have considered the effects of lyric content on aggression, and fewer still have incorporated behavioral measures in their methods.

\section{Definitions of Aggression}

Aggression has been defined as, "behavior whose goal is the injury of some object" (Berkowitz, 1962, p. 1). Bushman and Anderson (2001) prescribe the additional requirements that the perpetrator of an aggressive act must have purposeful and proximate (immediate) intent to harm the target and the target must be perceived as having motivation to avoid this behavior. Bushman and Anderson also argue that human aggression only occurs if the harmful act is directed toward an individual. Thus, the unintentional injury of another driver, or damage to the driver's car, in an auto accident would not constitute an aggressive act. Likewise, a dentist who performs a necessary root canal on a patient would not be committing an aggressive act. In this situation, the patient is willingly undergoing the procedure, and both parties believe that the act will be 
beneficial despite the pain involved. Another example of non-aggressive behavior that involves harm would be sexual sadomasochistic interaction between consenting adults. In such situations, the administration of pain is not considered aggressive because the submissive party receives or seeks punishment willingly.

Aggression is sometimes compared and contrasted with violence, which is defined as behavior motivated by a desire to cause extreme physical harm to another (Bushman \& Anderson, 2001). The primary difference between aggression and violence lies in the severity of the intended consequences of the perpetrator's actions. For example, pushing another person to the ground in order to hurt the person would constitute an aggressive act, but not necessarily violence. In contrast, pushing another person in front of a moving bus in order to cause severe injury or death would constitute a violent act. Unfortunately, it can be difficult to determine at what level of severity an act changes from one that is aggressive but non-violent to one that is violent.

In the literature, a distinction often is made between hostile and instrumental aggression. According to Feshbach (1964), "Hostile aggression is 'hot', impulsive behavior that is motivated by a desire to hurt someone; instrumental aggression is 'cold', premeditated behavior used as a means to some other end" (Bushman \& Anderson, 2001, p. 273). For example, a bully who beats a child in a moment of anger would be acting from hostile aggression. However, if the bully beat the child in order to extort the child's lunch money, then the bully would be acting from instrumental aggression. Although both acts involve aggression, they differ in terms of their ultimate goals. 
More recently, Bushman and Anderson (2001) have proposed that the hostileinstrumental dichotomy is no longer useful because it is incapable of capturing the complexity of human motives responsible for human aggression. They suggest that most acts of aggression are difficult to classify as being either purely hostile or instrumental. For example, a violent hate crime committed against a member of a minority group would probably include both hostile and instrumental components because the perpetrator is likely both angry and hoping to send a message to other members of the targeted group. As human aggression is a multifarious phenomenon, several prominent models and theories have emerged.

\section{Models of Aggression \\ Frustration-Aggression Model and Cognitive Neoassociation Theory}

The classic frustration-aggression model was proposed by Dollard, Doob, Miller, Mowrer, and Sears (1939). They postulated that the frustration of goal-oriented behavior with the realistic expectation of successful completion results in an inclination toward aggression. Although there were critics (e.g., Bandura, 1973; Zillman, 1979), the formulation was widely accepted until Berkowitz began to revise it in 1969.

Berkowitz modified the frustration-aggression formulation with the addendum that, "frustrations are aversive events and generate aggressive inclinations only to the extent that they produce negative affect" (1989, p. 71). Negative affect resulting in aggression could be the consequence of a variety of aversive stimuli, such as physical pain (e.g., Azrin, 1967) or psychological distress (e.g., Epstein \& Taylor, 1967), and 
objectionable environmental conditions such as high temperatures (e.g., Anderson \& Anderson, 1984). Even associations with unpleasant conditions can result in increased levels of aggression (Berkowitz, 1988). For example, Fraczek (1974) classically conditioned participants to pair receiving an electric shock with a color. After the conditioning regime, participants behaved more punitely toward a target when presented with the color alone.

Berkowitz also claimed that even justified aversive events would result in some measurable degree of aggression (1989). Dill and Anderson (1995) tested this hypothesis by comparing unjustified frustration, justified frustration, and no frustration on a timed origami task: they showed participants and a confederate how to fold an origami bird out of paper and then had them perform the task themselves under time pressure. The experimenter stated that they would only demonstrate the origami folding procedure once. The experimenter conducted the demonstration quickly, after which the confederate would complain about the difficulty of keeping up. The confederate then asked the experimenter to slow down to which the experimenter responded in a certain way depending on frustration condition. In the no frustration condition, the experimenter apologized and agreed to repeat the demonstration more slowly. In both frustration conditions, the experimenter made an excuse for why he or she could not slow down. In the unjustified frustration condition, the experimenter replied that he or she wanted to finish the study quickly so he or she could leave to meet a significant other. In the justified frustration condition, the experimenter explained that his or her supervisor had scheduled another test in the same room immediately afterward, and that he or she was 
being pressured to finish the study as quickly as possible. At the end of the study, the participants were asked to rate the likeability and competence of the experimenter on a questionnaire that was described as being used by the university to evaluate the performance of experimenters and to determine whether they would be eligible for merit awards and financial assistance or subjected to disciplinary action. The results indicated that no frustration yielded the least amount of aggression toward the experimenter (i.e., positive ratings), justified frustration yielded a moderate amount of aggression, and unjustified frustration yielded the most amount of aggression (i.e., negative ratings).

Building on Berkowitz's work, the cognitive neoassociation theory of aggression proposes that emotions and behaviors fuse with aggressive cognitions to form an associative schema of aggression in memory (Collins \& Loftus, 1975). Semantically related concepts develop associations with other concepts with which they are frequently and simultaneously activated (Berkowitz, 1984). This idea explains why certain stimuli may become associated with specific cognitions or emotions. Anderson and Bushman (2002) give the example of the word "gun" becoming associated with words such as hurt, harm, shoot, or kill. Thus, the mere thought of a gun can prime violent concepts associated with its use.

\section{Social Learning Theory}

Social learning theory posits that the repertoire of social behaviors may be acquired from observing others receive reinforcement or punishment for their actions (Bandura, Ross, \& Ross, 1961). For example, in one important study, nursery school students imitated the aggressive behavior they observed while watching a film (Bandura, 
Ross, \& Ross, 1963). Bandura (1978) later applied this theory specifically to the learning of aggression. He was critical of the drive theory explanation of aggression proposed by Dollard et al. (1939), who argued that frustration causes general emotional arousal that one may reduce by behaving aggressively. Instead, Bandura (1973) emphasized that what one learns socially will determine how this arousal will be channeled.

\section{Script Theory}

Huesmann built upon cognitive neoassociation and social learning theories with a model that involves the learning of aggressive behavioral scripts $(1986,1998)$. When activated in social situations, these scripts provide guidelines for behavior. Script theory was developed by Schank (1975, 1982, 1986; Schank \& Abelson, 1977), and describes how behaviors are strongly linked together and associated such that one serves to prime the next step in the chain, forming a dynamic model of memory. For example, a retaliatory script might include experiencing pain, perceiving it as being intentional, feeling embarrassed and/or ridiculed, experiencing anger, retaliating to restore selfimage, using a weapon to retaliate (adapted from Anderson \& Bushman, 2002, p. 30). Repetition of a script increases the strength of linked behaviors through rehearsal and by forming new associations with other concepts and schemas in the memory.

\section{Social Interaction Theory}

Social interaction theory deals with how aggressive behaviors often involve coercive motives (Tedeschi \& Felson, 1994). It is concerned with identifying the ultimate goals that instrumental aggressive actions aim to realize. According the theory, aggressive actions result from the attempt to satisfy three general classes of goals: (a) to 
manipulate, control, or influence others for gain; (b) to promote or seek justice, protest, punishment, or revenge; and (c) to assert and defend social identities. Tedeschi and Felson (1994) explain that any combination of these coercive motives can explain instrumental aggressive action.

\section{Excitation Transfer}

Whereas the social interaction theory focuses on explanations for instrumental aggression, the excitation transfer model pertains more to hostile, affectively driven aggression. The excitation transfer theory of aggression incorporates three factors to explain aggressive behavior: (a) emotional physiological arousal, (b) learned patterns of behavior, and (c) higher-order cognitive processes that monitor and evaluate emotions and behaviors (Zillmann, 1979). The theory asserts that the effects of physiological arousal last longer than are usually expected, and that lingering arousal may become cognitively misinterpreted. According to Zillmann, "while cognitive processes modify excitatory activity, excitatory activity is likely to influence cognitive processes in turn" (1983, p. 82). Because arousal may dissipate slowly, an individual may misattribute his or her emotions to a subsequent event that initially did not elicit the arousal. Zillmann describes how high degrees of physiological arousal can interfere with cognitive processes that promote restraint. The resulting disinhibition can thus lead to impulsive aggressive behavior.

Zillmann disagrees with the notion that aggression is primarily an instrument for personal gain, explaining, "contrary to the impression created by violence-ridden fiction 
and television drama in particular, aggressive behavior is not primarily motivated by the pursuit of incentives" (1979, p. 300).

\section{General Aggression Model}

The general aggression model (GAM) was proposed as a means to consolidate many of these theories into a more parsimonious model (Anderson \& Bushman, 2002). Because it offers a larger integrative framework, proponents of the GAM believe it provides several conceptual advantages over the use of smaller-scale theories. For example, proponents of the GAM believe it can explain aggressive acts with more than one motive (e.g., hostile and instrumental), is useful for the development and implementation of intervention strategies, and accounts for developmental issues that are of concern to parents and educators. The GAM contains three episodic routes, which include inputs, routes, and outcomes.

\section{Inputs}

The GAM describes two types of inputs: person and situational. According to Anderson and Bushman, "person factors comprise an individual's preparedness to aggress" (2002, p. 35). Person factors in the GAM include personality traits, gender, personal beliefs, attitudes and values, long-term goals, and previously learned scripts. Situational factors include aggressive cues, provocation, frustration, pain or discomfort, the use of alcohol, stimulants, or other drugs, and incentives for aggression. 


\section{Routes}

The two classes of inputs feed into and influence the present internal state, which includes the individual's cognitions, level of arousal, and affect (i.e., routes). Anderson and Bushman (2002) suggest a high degree of interconnectedness exists among these three internal factors. They point to Schachter and Singer (1962) as support for how cognition and arousal produce affect and Bower (1981) as support for how affect influences cognition and arousal.

According to the GAM, hostile cognitions are particularly important, and they are influenced by two major factors: Cues and scripts. Aggressive cues, such as the presence of guns or other weapons, can prime aggressive cognition. For example, frustrated individuals behave more aggressively when they are in the presence of a gun than when they are in the presence of sporting equipment (Berkowitz \& LePage, 1967). Anderson and Bushman warn that the "frequent activation of a concept results in its becoming chronically accessible" (2002, p. 38). This can result in aggressive behavioral scripts being encoded, rehearsed, and subsequently retrieved and acted upon in social situations (Huesmann, 1988).

Anderson and Bushman (2002) explain that arousal potentially has three effects on aggression. First, arousal may be labeled as anger incorrectly, which in turn may enhance aggression in certain situations via excitation transfer (Zillmann, 1983). Second, high arousal states may strengthen an individual's dominant (well-learned) response in a situation, which may be to react in an aggressive manner. Third, arousal that is too intense or too weak may be perceived as aversive, which may elicit aggressive behavior. 
Affect may lead to aggression through inputs that cause physical or psychological pain. Azrin (1967) has demonstrated that members of various species of laboratory animals will attack another creature in their cage after exposure to electric shock, even when such behavior is not paired with termination of the shock. Competition that yields frustration is another example of how affect may increase aggression, as demonstrated by the "Robbers Cave" study (Sherif, Harvey, White, Hood, \& Sherif, 1961). In the "Robbers Cave" study, competition over limited resources increased displayed aggressive behaviors between groups of school-aged boys. Bandura's theory of moral disengagement suggests that one's attitudes may change in order to facilitate aggression (Bandura, Barbaranelli, Caprara, \& Pastorelli, 1996). He proposes that moral selfsanctions for prosocial behavior can be disengaged allowing for reprehensible actions toward others. These mechanisms include moral justification for the act, displacement or diffusion or responsibility, minimizing or ignoring the consequences, or blaming and/or dehumanizing the victim. Exposure to media violence also shows an association with (a) an increase in aggressive feelings (Anderson et al., 2003), (b) learning of aggressive behavior (Bandura, Ross, \& Ross, 1963), and (c) learning of aggressive scripts (Huesmann, 1986).

\section{Outcomes}

There are several processes involved in the outcomes portion of the GAM. According to Anderson and Bushman (2002), the relatively automatic process of situational appraisal occurs first. If the situation is important and the individual has sufficient time, cognitive capacity, and awareness, then there is an opportunity for 
reappraisal of the situation, which may make aggression less likely. If sufficient resources are unavailable, however, then an impulsive aggressive action is more likely to occur. Presumably, if resources are available and the situation is important, then the individual will cycle through the reappraisal process until a thoughtful line of action is determined. Although thoughtful action may reflect an attempt to respond less aggressively, it is possible that thoughtful action may involve a more thoroughly plotted and well planned aggressive act. The GAM model suggests that not only can the present internal state influence outcomes, but outcomes also may reciprocally influence the internal state.

\section{Violent Media}

Doob and Kirshenbaum (1973) found evidence that provocation along with exposure to violent media (a film depicting aggression) can result in increased physiological arousal. In his doctoral dissertation, Day (1980) explored the effects of excitatory potential and hedonic valence of music. This study consisted of four different experimental music conditions and a non-music control condition. In the music conditions, participants listened to music that either was stimulating and pleasing, stimulating and displeasing, sedating and pleasing, or stimulating and pleasing. The music was pilot tested and classified by participants who did not take part in the actual study. Results of Day's study indicate that provoked participants retaliated more against a confederate when exposed to music that was either stimulating or hedonically displeasing in nature than did unprovoked participants and provoked participants who listened to sedating music, hedonically pleasing music, or no music. 
Although provocation seems to be a factor in aggression, studies also have found that unprovoked participants will aggress when exposed to violent media alone. Research using sexually explicit videos has shown that even unprovoked males will aggress against a female confederate after they watch violent pornography that portrays a woman enjoying violent sex (e.g., Donnerstein, 1980; Donnerstein \& Berkowitz, 1981). Similarly, Zillmann and Weaver (1999) conducted a study manipulating both provocation and long-term exposure to violent films. Participants watched either violent or nonviolent movies for four days and then were asked to participate in a person-perception study. The participants received either positive or negative feedback on their performance from a research assistant. After completing the person-perception task, the principal investigator asked the participants to provide an evaluation of the research assistant that would affect the assistant's eligibility for another assistantship and continued financial aid in the next year. Zillmann and Weaver found that exposure to either the violent movies or the negative feedback from the research assistant was enough to elicit negative feedback about the research assistant from participants. Counter to the researchers' hypotheses, aggressive behavior was not conditional upon experiencing both provocation and exposure to violent media.

Most of the research examining the effects of media violence on aggression has involved visual media such as television programs or movies (Bandura, Ross, \& Ross, 1963; Josephson, 1987; Malamuth \& Check, 1981; Zillman \& Weaver, 1999). Several recent studies report similar findings when violent media is operationalized as violent video games (Anderson \& Dill, 2000; Cooper \& Mackie, 1986; Gentile, Lynch, \& 
Linder, 2004). However, little research has investigated the effects of exposure to music containing violent lyrics on aggression. Furthermore, those studies that have investigated the effects of violent music on aggression have done so by using music videos as stimuli (e.g., Hansen \& Hansen, 1988; Peterson \& Pfost, 1989; Rustad et al., 2003; Smith \& Boyson, 2002). Use of music videos is problematic because they confound the auditory and visual modalities of stimulus presentation. In addition, a number of the studies used correlational designs rather than experimental designs, which limits the ability to draw causal conclusions (e.g., Took \& Weiss, 1994; Waite, Hillbrand, \& Foster, 1992). Finally, those studies that have employed violent music measured aggression by assessing attitudes toward women, which may not generalize to behavior (e.g., Barongen \& Hall, 1995; Lawrence \& Joyner, 1991; Peterson \& Pfost, 1989; Wester, Crown, Quatman, \& Heesacker, 1997).

Perhaps the most compelling evidence of the effect of listening to violent lyrics on aggression comes from a series of studies by Anderson, Carnagey, and Eubanks (2003) that report an increase in access to aggressive thoughts following exposure to songs with violent lyrics. Even listening to songs with "humorous-violent lyric content" led to elevated scores on a self-report state hostility scale. The authors report that participants exposed to a song with violent lyrics reported higher levels of state hostility, were more likely to interpret an ambiguous stimulus as involving aggressive elements, and showed increased relative accessibility to aggressive words compared to participants who listened to a song with non-violent lyrics. However, although Anderson et al. found 
that violent lyrics primed access to hostile thoughts, they failed to take behavioral measures of aggression.

In another study that did attempt to measure aggressive behavior, Barongan and Hall (1995) had male participants listen to either neutral or misogynous rap music, after which the participants viewed neutral, sexual-violent, and assaultive film vignettes. After viewing the vignettes, participants were asked to choose one of the vignettes to show a female confederate. Of those listening to the misogynous rap music, 30\% percent chose the assaultive vignette whereas $70 \%$ chose the neutral vignette. Of the participants listening to the neutral rap music, $93 \%$ chose the neutral vignette with the remainder either choosing the assaultive or sexual-violent vignette. One problem with this study is that the misogynous songs used in the experiment, "suggested that women enjoy coercive sex" (p. 200). It is thus difficult to determine if the results were due to listening to violent lyrics, to the effect of portraying women as enjoying violent sex (e.g., Donnerstein, 1980; Donnerstein \& Berkowitz, 1981), or to a potential interaction of these two factors. In addition, because only rap music was used, it is unclear whether the effects would generalize to other genres of music. Consequently, the present research was designed to examine the effects of songs with violent lyrics on a clear behavioral measure of interpersonal aggression.

\section{Music and Emotion}

Another important topic for consideration involves the research on music and emotion. Results of a study by Rickard (2004) indicate the most consistently reported 
reason participants listened to music was to modify their emotions. Trainor and Trehub (1992) have reported that children as young as 4 years can reliably associate excerpts from Prokofiev's "Peter and the Wolf" and Saint Saens' "Carnival of Animals" with pictures of the animals. They gave emotion-laden justifications to their responses, such as describing the wolf excerpt as sounding "scary." Further, a cross-cultural study has provided evidence that individuals can correctly identify the emotions being portrayed in the music of a foreign culture with a completely different musical system at better than chance odds (Fritz et al., 2009).

There is evidence that music can induce emotion directly through activation of the autonomic nervous system, as observed through changes in heart rate, respiration rate, blood pressure, and galvanic skin response (Witvliet, 1997). Commonly reported physiological responses to music related to emotion include shivers down the spine, laughter, tears, and a "lump in the throat" (Sloboda, 1991). Music also appears to activate cortical systems associated with emotion, including circuits of the frontal lobe (Trainor \& Schmidt, 2003).

One implication of these findings is that songs with violent lyrics may enhance aggression in at least two ways. First, the violent lyrics contain aggressive semantic themes, which may trigger internal routes that lead to aggression. Second, in many instances writers of music will likely tend to imbed violent lyrics in music that "sounds aggressive.” Thus, songs with violent lyrics are complex aggressive stimuli that may influence listeners through multiple inputs simultaneously. 


\section{Present Research}

This study involved the manipulation of songs with violent and non-violent lyrics across several genres to generalize across musical style and arousal intensity. Violent and non-violent songs performed by the same artists were used as comparison stimuli.

Participants wrote a brief essay, listened to music containing either violent or non-violent lyric content, and then received either negative or praising feedback about their essay from an ostensible second participant. Next, participants were given the opportunity to evaluate an essay written by the second participant, which constituted the measure of aggressive behavior. In terms of the GAM, the present study focused on how situational rather than personal factors influence aggression. In line with the GAM, the following hypotheses were tested: 


\section{HYPOTHESES}

Hypothesis 1: Inputs. Participants will perceive songs with violent lyrics as being more violent than songs with non-violent lyrics.

Hypothesis 2: Routes. Exposure to music with violent lyrics and receipt of negative feedback will both enhance negative affect.

Hypothesis 3: Outcomes. Exposure to music with violent lyrics (an aggressive prime) and receipt of negative feedback will interact to affect aggression. Specifically, negative feedback will increase aggression and exposure to music with violent lyrics will enhance this effect. 


\section{METHODS}

\section{Participants}

Forty-two participants (31 women, 11 men) from the University of WisconsinOshkosh psychology department's participant pool were randomly assigned to one of four conditions in a 2 (lyrics: violent vs. non-violent) x 2 (feedback: positive vs. negative) factorial design. Participants volunteered for the study to fulfill a class research participation requirement or to receive course extra credit. There were 8 participants in the violent lyrics/negative feedback condition, 12 in the non-violent lyrics/negative feedback condition, 12 in the violent lyrics/positive feedback condition, and 10 in the non-violent lyrics/positive feedback condition.

\section{Procedure}

Participants were run through the study individually. Upon arrival, participants were greeted by an experimenter who led them to a small room that was approximately 10 feet by 10 feet in dimension. The participants were seated at a desk and given the informed consent document and an instruction sheet (see Appendixes A and B). The experimenter explained that the purpose of the study was to investigate the effect of peer feedback on subsequent performance on essay writing tasks, with the ultimate goal of helping to develop a new peer review program for first semester freshmen to improve their writing ability and critical thinking skills. The experimenter explained that the program was being developed for possible use by the university. 
The experimenter then directed the participants to the informed consent document, and the instruction sheet outlining these procedures. Anonymity was assured, and it was explained that another participant also would be taking part in the study and would be met by the experimenter in a few minutes. The experimenter further explained that the study was staggered with different starting times so that the two participants would never meet. The purpose of this procedure was to allow the participants a forum in which they could anonymously and freely express their opinions. The experimenter then left the room for a few minutes while the participants signed the informed consent and read the instructions sheet.

Upon returning, the experimenter collected the informed consent document and instructions sheet, and then answered any questions the participants had. Next, participants were asked to complete an Essay Task (see Appendix C). Upon exiting the room, the experimenter pretended to set up the other participant in the adjacent room. After 10 minutes, the experimenter returned to collect the essay and explained that the other participant was still working on his or her essay task. Because the second participant started the study later, it was explained that the participant would not be finished for about 5 more minutes. The experimenter then asked the participants if they would be willing to help out with a brief pilot study involving music. The experimenter suggested that rather than waiting with nothing to do, the participants might like the opportunity to listen to some music and help out with another study.

The pilot study was described as another graduate student's project that involved selecting songs for a future study investigating preference for different musical genres 
and lyrical themes in college students of various majors. In reality, this was not a separate pilot study conducted for another graduate student, but was presented as a separate study in order to reduce any suspicion the participants may have had about the relation of the music to the actual study. The participants then were provided with a second informed consent document and instruction sheet for the pilot study (see Appendixes D and E). The experimenter then went into the adjacent room under the pretense of dropping off the participant's essay to be reviewed and rated. Upon returning, the experimenter collected the informed consent, and provided the participants with another instruction sheet, a Minidisc player with headphones, and a Music Questionnaire (see Appendix F). This questionnaire contained items probing each participant's mood and arousal, their ability to understand the lyrics, and the amount of violence they perceived to be contained in the lyrics. Forms for the music pilot study were printed in a slightly different font and layout format to improve the credibility of it actually being an unrelated study.

Participants then were given instructions on how to operate the Minidisc player, and were told to start the player after reading the instruction sheet. Preceding the song was a brief recording in a female voice describing the music-rating task (see Appendix G). It was explained that by the time the pilot study was completed the other participant should be finished with his or her essay, and that the original study would then resume. Participants were told that they would listen to one song and then rate its lyrics and musical aspects. The experimenter then left the room and asked the participants to open the door once they were finished filling out the music questionnaire. The experimenter was blind to which song each participant was provided until the conclusion of the study. 


\section{Music Conditions}

The music used in this study was categorized as either having violent or nonviolent lyric content. Three categories of music were selected: rap, hard rock, and pop/rock. Although participants were exposed to only one song in the study, three genres of music were selected in order to control for any potential genre effects. Each music category contained a violent and non-violent song, which resulted in a total of 6 songs, 3 of which contained violent lyrics, and 3 of which contained non-violent lyrics. See Appendix $\mathrm{H}$ for a list of all songs used in the lyric conditions.

All songs were coded for aggressive primes, and were then tallied to measure the amount of aggressive content. Aggressive primes included words or phrases with clearly aggressive or violent connotations (e.g., "death”, “gun”, “murder”, "I'll come and take your life away”, etc.). The violent rap, hard rock, and pop/rock songs contained 27, 10, and 13 aggressive primes, respectively. The non-violent group of songs contained only one potentially aggressive prime, which was in the rap genre. The website www.songmeanings.net was accessed to research the thematic content of the songs as perceived by other listeners. This website contains message postings by users expressing what they believe the song lyrics to mean. For example, one user commented on the lyrics of Tool's “Jerk-Off” (hard rock, violent lyric condition) by saying, "It's pretty obvious as to the meaning of this great song: Being pissed off at someone so much that you want to beat the shit out of them" (DownedSystem, 2002). Another user commented on Tool's "Cold and Ugly" (hard rock, non-violent lyric condition) by writing, "I see it as a girl who is maybe beautiful on the outside hides much of her true self on the inside. As 
with many of Tool's songs, a person should learn to wade in that dark side of themselves; all the things that they refuse to accept and fear from themselves" (Chino69, 2002). See Appendix I for the printed lyrics to the songs in this study.

Songs ranged in length from $3 \mathrm{~min} 44 \mathrm{sec}$ to $4 \mathrm{~min} 36 \mathrm{sec}$. The songs were all andante in tempo, ranging from 82 to 98 beats per minute. The computer software MP3 Gain 1.2.5 (Sawyer, 2005) was used to normalize the volume of all tracks to $89 \mathrm{~dB}$. The music was presented on a Sony Net-MD Minidisc player model MZ-N505 with Sony MDR-CD60 Digital Reference Dynamic Stereo Headphones.

\section{Feedback Conditions}

After participants completed the Music Questionnaire, the experimenter returned with participants' feedback purportedly from the second ostensible participant. The experimenter was blind as to the type of feedback each participant received until the conclusion of the study. In addition to receiving feedback, participants were also provided with the second ostensible participant's essay and a blank Feedback Form (see Appendix J) used to review and rate the essay. The Feedback Form participants received and were asked to use included items that asked them to rate the organization, breadth of vocabulary, spelling and grammar, development of noteworthy ideas, and overall effectiveness of the essay. Participants were randomly assigned to receive either positive or negative ratings of their essay. Those in the positive feedback condition received a review of general praise and positive ratings from the ostensible second participant. Participants in the negative feedback condition received harshly critical yet vague statements about their essay, and below average scores on all measures. The feedback 
and essay received were purportedly produced by the second ostensible participant. See Appendixes $\mathrm{K}$ and $\mathrm{L}$ for the essays participants were asked to review, and Appendixes $\mathrm{M}$ - P for copies of the feedback provided to participants. All feedback and essays were written in either male or female handwriting to match each participant's gender. Participants always were paired with a second ostensible participant of the same gender in order to eliminate any potentially confounding cross-gender effects. The participants were instructed to read their feedback before rating the other participant's essay. Participants used a blank Feedback Form to rate the second ostensible participant's essay after exposure to a song and receiving feedback about their own essay. The mean rating on all items on the Feedback Form was used to assess the amount of aggression against the second ostensible participant. High scores indicated positive ratings, while low scores indicated negative ratings. The experimenter then left the participant to their rating task, and returned several minutes later.

At this point, participants were given the Quality of Feedback Questionnaire (see Appendix Q) to gather information on their feelings about the feedback they received. This questionnaire contained items asking about whether participants viewed the feedback they received as being fair, whether they experienced insult or anger after receiving the feedback, and the extent to which they felt the second participant was competent. When the experimenter returned to collect the Quality of Feedback Questionnaire, participants were asked to verbally answer a few questions about the study before beginning the second essay. At this point, the experimenter assessed participants' general reactions, probed for suspicion regarding the true nature of the experiment and 
the veracity of the second participant and the music pilot study. Each participant was rated by the experimenter on a 0 to 5 Likert scale regarding their level of suspicion to the true nature of the study $(0=$ no suspicion, $5=$ participant accurately describes true nature of study in great detail). The experimenter then transitioned into a thorough debriefing and dehoaxing with each participant. The experimenter informed participants that the study was actually over, that they would not have to write a second essay, and that all their questions would be answered with candor. During the debriefing process, participants were informed about the true nature of the study, the procedures involved, and the reasons why deception was employed. 


\section{RESULTS}

Inputs: Ratings of Violence

A 2(lyric) x 2(feedback) ANOVA was conducted to evaluate the hypothesis that participants would perceive songs with violent lyrics as being more violent than songs with non-violent lyrics (Hypothesis 1). Although participants had not received feedback at this time in the study, feedback was included in the analysis as a way to assess the success of random assignment to the feedback conditions. See Table R-1 for means and standard deviations of the main analyses for items on the Music Questionnaire. As shown in Figure S-1, there was a statistically significant main effect for the lyric condition, $F(1$, $38)=24.211, p<.001$, partial $\eta^{2}=.389$. Consistent with Hypothesis 1 , participants in the violent lyric condition rated the song lyrics as being more violent $(M=3.700, S D=$ 1.342) than did participants in the non-violent lyric condition $(M=1.727, S D=1.120)$. The ANOVA indicated neither a main effect for feedback nor a significant interaction between lyric condition and feedback conditions (both $p s>0.50$ ).

\section{Routes: Mood Ratings}

A 2 (lyric) x 2(feedback) ANOVA was conducted to evaluate the effect of lyric content on self-reported mood after participants were exposed to the music (see Figure S2). There was a statistically significant main effect for lyric content, $F(1,38)=12.119, p$ $=.001$, partial $\eta^{2}=.242$. Consistent with Hypothesis 2, participants in the non-violent lyric condition reported less negative $\operatorname{mood}(M=3.773, S D=.975)$ than did participants 
in the violent lyric condition $(M=2.600, S D=1.095)$. Neither the interaction effect nor the main effect for feedback type reached statistical significance for self-reported mood ratings $(p s>.65)$. It is important to note that participants were not yet exposed to feedback when this measure of mood was acquired.

A 2 (lyric) x 2 (feedback) ANOVA was conducted to evaluate whether receiving negative feedback increased negative affect. An index for negative affectivity was created from the Quality of Feedback Questionnaire as a dependent measure for this analysis. The index included items 6 (How frustrated did you feel after receiving feedback?), 7 (How angry did you feel after receiving feedback?), 8 (Did you feel insulted by the feedback?), and the reverse score of item 5 (How good did you feel after receiving feedback?). The negative affectivity index thus involved a composite of self-reported frustration, anger, sentiments of insult, and the inverse feeling of goodness. A reliability analysis for the internal consistency of the four items resulted in Cronbach's $\alpha=0.87$. It is important to note that participants had been exposed to both the lyric and feedback conditions by the time they completed this questionnaire.

Results of the two-way ANOVA indicated a significant main effect for feedback type, $F(1,38)=17.159, p<.001$, partial $\eta^{2}=.311$, but not for lyric content, $F(1,38)=$ $1.191, p=.282$, partial $\eta^{2}=.030$. The interaction effect was marginally significant, $F(1$, $38)=4.078, p=.051$, partial $\eta^{2}=.097$. As seen in Figure S-3, consistent with Hypothesis 2, participants who received negative feedback reported significantly higher levels of negative affect $(M=2.238, S D=.883)$ than did those who received positive feedback $(M$ 
$=1.307, S D=.475$ ). See Table R-2 for means and standard deviations of the four items from the Quality of Feedback Questionnaire that were used in these analyses.

\section{Outcomes: Aggression}

A 2 (lyric) x 2 (feedback) ANOVA was conducted to evaluate the hypothesis that exposure to songs with violent lyrics and negative feedback would interact to increase aggression (Hypothesis 3). An index of aggression was created as a dependent measure incorporating all of the items on the Feedback Form. The index included ratings of the quality of the ostensible second participant's essay, including elements of its organization, vocabulary, spelling and grammar, development of noteworthy ideas, and overall effectiveness. Higher scores on the index reflect more favorable ratings of the other participant's essay. A reliability analysis for the internal consistency of the 5 items resulted in Cronbach's $\alpha=0.93$. It is important to note that participants had been exposed to both the lyric and feedback conditions by the time they completed this questionnaire.

As seen in Figure S-4, results of the two-way ANOVA again indicated a significant main effect for feedback type, $F(1,38)=19.825, p<.001$, partial $\eta^{2}=.343$. As expected, participants who received positive feedback gave the ostensible second participant higher ratings $(M=5.173, S D=1.255)$ than did those who received negative feedback $(M=3.665, S D=.736)$. However, contrary to Hypothesis 3 , the interaction between lyric and feedback was not statistically significant, $F(1,38)=1.684, p=.202$, partial $\eta^{2}=.042$. In addition, the main effect for lyric condition also failed to achieve 
statistical significance, $F(1,38)=.649, p=.426$, partial $\eta^{2}=.017^{1}$. See Table R-3 for means and standard deviations of the items from the Feedback Form used in these analyses.

${ }^{1}$ An analysis that included potential covariates indicated that level of suspicion had little impact on these findings. Analyses using the individual items in the Music Questionnaire (e.g., frequency of listening, level of violence in the lyrics, liking of lyrics, liking of music, etc.) indicated that only clarity of the lyrics was a significant covariate when the aggression measure was used as the dependent variable, $F(1,37)=4.196, p$ $=.045$, partial $\eta^{2}=.102$. Specifically, participants who rated the lyrics of the song as being less clear gave lower ratings of the ostensible participant's essay. However, further analyses revealed no appreciable difference between the means for lyric clarity by the violent content of the lyrics. 


\section{DISCUSSION}

The results of the present study provide mixed support for the research hypotheses made using the General Aggression Model (Anderson \& Bushman, 2002), and based upon the overall consensus of previous violent media studies (Anderson, Carnagey, \& Eubanks, 2003; Anderson et al., 2003; Huesmann, Moise-Titus, Podolski, \& Eron, 2003). As predicted by Hypothesis 1, participants rated songs with violent lyrics as being significantly more violent than songs with non-violent lyrics. Participants also rated the lyrics of songs with non-violent lyrics to be happier than songs with violent lyrics. These results are similar to those of Barongan and Hall (1995) who reported that most participants in their study were accurately able to identify the themes of songs as being either neutral in nature or containing references to sex and/or violence. Furthermore, Hanson and Hanson (1991) have reported that listeners are capable of accurately identifying themes in music relating to sex, suicide, violence, and the occult on a schematic level regardless of whether or not the lyrics are clearly decipherable.

Because participants were able to differentiate accurately and reliably between violent and non-violent lyrics, it seems reasonable to assume that the violent lyric manipulation was successful. Consequently, the present findings suggest appropriate instantiation of the input phase of the General Aggression Model (GAM).

As for their mood and affect, participants exposed to a song with non-violent lyrics reported higher, more positive mood levels than participants who listened to a song containing violent lyrics. However, a statistically significant difference was not observed 
between lyric conditions on a measure of negative affect completed post receipt of feedback. Although not statistically significant, it is interesting to report that a trend in the opposite direction than hypothesized emerged. Participants exposed to a song with non-violent lyrics rated feeling higher levels of negative affect than those listening to a song with violent lyrics. There are a number of possible explanations for these findings. First, the affect rating was provided later in the study than the mood rating, and it is possible that the emotional impact of the song had attenuated or somehow changed by this point. Thus, this difference between reported mood and affect may be the artifact of some sort of sequencing or maturational factor. Second, while the measure of negative affect was an index of several items, the measure of mood was attained from a single item. Psychometric differences between these two variables may explain the seemingly contradictory findings. It is also possible that there are some differences between the underlying factors of what these two variables were actually measuring.

Although lyric content was not appreciably related to affect, the type of feedback participants received was associated with this variable. As predicted, those who received negative feedback reported higher levels of negative affect than did participants exposed to positive feedback. Unexpectedly, there also was a marginally significant interaction such that participants receiving negative feedback and exposed to a song with non-violent lyrics reported the highest levels of negative affect. These results provide mixed support for Hypothesis 2, and are not readily explainable in terms of the routes described by the GAM (mood, arousal, cognition). They do suggest that songs with violent lyrics have some effect on the present internal state, although, not as hypothesized. 
Regarding Hypothesis 3, the overall behavioral outcome of the study indicates that feedback type was a major factor in predicting aggression. The effect of provocation was significant such that participants receiving negative feedback were much harsher in their ratings of the ostensible participant than were participants who received praise for their essays. Many other studies evaluating the effect of provocation on subsequent aggression have reported similar results (e.g., Bettencourt, Talley, Benjamin, \& Valentine, 2006; Epstein \& Taylor, 1967; Pederson, Gonzales, \& Miller, 2000; Taylor, 1967). Furthermore, those receiving positive feedback rated the feedback they received as being fairer than did those in the negative feedback condition.

In contrast to the effect of negative feedback, the presence or absence of violent lyrics was not associated with aggressive behavior. Nor was the hypothesized interaction effect found, which predicted that participants exposed to songs with violent lyrics and negative feedback would be the most aggressive. Due to the significant main effect of provocation, it seems reasonable to assume that the dependent variable of aggression was sufficiently sensitive to the factors manipulated in this study. If exposure to a song with violent lyrics does indeed affect subsequent aggression, then the association is much too small to be detected in this study.

It is important to note that even Anderson, Carnagey, \& Eubanks (2003) have reported that the literature relating to the influence of violent lyrics on aggression has provided mixed results. For example, Wanamaker and Reznikoff (1989) reported a failure to find a significant difference in hostility scores between participants listening to violent or nonviolent rock songs. However, current aggression theory (e.g., Anderson \& 
Bushman, 2002) still suggests that exposure to a song with violent lyrics would likely result in increased subsequent aggression. It is thus proposed that the GAM would likely benefit from more elaboration about contextual and interactional factors necessary for aggression to occur.

\section{Limitations}

In addition to the potential implications of this study, it is important to observe some of its limitations. One important limitation relates to sample size and unequal assignment to experimental condition. The overall sample was small $(n=42)$, and the assignments of participants was unequal across conditions. Although the small sample still resulted in statistically significant findings, a larger sample that was equally distributed would have allowed for more confidence that the null finding for the media main effect on aggression was not the result of a Type II Error. Another limitation of the small sample is that song genre effects could not be effectively investigated. Further, this research design does not allow one the ability to separate potential musical effects from lyric effects. Thus, this design would not allow for more fine-grained conclusions regarding the process by which songs with violent lyrics might affect aggression.

Related to sampling limitations, the sample was primarily female (31 females, 11 males). It is possible that differences in how men and women process and react to violent media and negative affect could have influenced the findings of this study. Bettencourt and Kernahan (1997) report that men are in fact more aggressive than are women when violent cues are present than when they are in neutral, unprovoked conditions. However, 
it is important to note that no sex difference in aggression was found when conditions that involved joint exposure to violent cues and aversive provocation were examined. With this in mind, it does not seem that an unequal sampling of gender would significantly detract from the validity of these results, as violent cues and aversive provocation were both successfully manipulated in the present study.

Next, the exposure time to the songs was limited, and it is possible that participants would require longer-term exposure to media violence for an appreciable effect on aggression to emerge. For example, Zillman and Weaver (1999) found a media violence effect after exposing participants to full-length violent movies over the course of several days. However, Higgins, Rholes, and Jones (1977) have reported that even the exposure to a single word can initiate a priming effect. Berkowitz has reported priming effects from even brief exposure to weapons. For example, frustrated individuals engage in more aggressive behaviors when in the presence of a gun than in the presence of a badminton racquet (Berkowitz \& LePage, 1967). Geen and Thomas (1986) also have given an account of immediate aggression in response to media violence. In the present study, participants in the violent lyric condition were exposed to at least ten aggressive primes. According to the previously cited priming literature, this should be adequate exposure to activate a priming effect.

Another limitation of the study relates to the dependent measure of aggression. Because this paradigm for studying aggression is new, the reliability of the measure is uncertain. Furthermore, the measure has not been cross-validated with other aggression measures. However, this novel paradigm is considered to have certain advantages over 
existing measures in that it is a covert measure of aggression with low experimental demand. Participants expressed that they were not aware that the study was actually investigating aggressive behavior during the debriefing at the conclusion of the study.

\section{Future Directions}

Considering the findings and limitations, there are a number of directions future research could take. In addition to addressing the limitations previously described, it would be beneficial to explore if and how competitive situations interact with media violence to possibly facilitate aggression. Future research is also recommended to further investigate the effect media violence has on physical forms of aggression. Another recommendation is to investigate possible order effects for the presentation of media violence and provocation. Further, research is suggested to investigate the effect clarity of song lyrics has on aggression. Additional research is recommended to assess the reliability and validity of the aggression measure utilized in this study. Finally, it also would be useful to study the effects of longer-term exposure to aggressive primes to help assess just how influential violent media is on promoting aggressive behavior.

\section{Implications}

In addition to possible theoretical implications for the GAM, the present study introduces a new paradigm for investigating aggression through the manipulation of violent media and negative feedback. The new essay writing/critiquing paradigm detailed in this study is seen as having a high degree of ecological validity for the studied sample 
of college students because students are frequently expected to review and evaluate their own work as well as the work of others. Because analyzing an essay likely requires more deliberate thought than such tasks as administering a shock or noise blast, participants may be able to engage in more thoughtful forms of decision making when planning their behavior. Further, this task is not likely to be seen by participants as being competitive in nature. Tasks involving playing a competitive game where the winner is allowed to punish the loser through shocks or noise blasts are thought to likely confound aggressiveness with competitiveness. These paradigms also are seen as setting the norm or expectation that it becomes acceptable, if not encouraged, to aggress against the other participant. In contrast, this study includes a procedure that is not easily confused with competiveness, and provides an ambiguous social context where the participant is likely uncertain about the appropriateness of engaging in an aggressive act. Overall, the procedure presented in this study has shown to be effective in manipulating and measuring negative affect and interpersonal aggression in a laboratory setting. It may serve as a useful tool for further investigation into the effects of other forms of violent media or other violent primes on subsequent aggression.

In terms of implications outside of the laboratory setting, results of this study suggest that the effects of provocation may be a more pressing concern for parents, teachers, researchers, and policy makers than those related to the effects of listening to songs with violent lyrics. 


\section{Conclusion}

The results of the current study provide further evidence that provocation is related to increased interpersonal aggression. Participants who received insulting negative feedback from a second ostensible participant were more critical in their feedback of this participant. Further, participants were found to be able to identify themes of violence in song lyrics accurately and reliably. Exposure to songs with violent lyrics was also subsequently associated with lower self-reported mood than participants exposed to songs with non-violent lyrics. However, exposure to a song containing violent lyrics was not related to an increased display of interpersonal aggression as was hypothesized. Failure to find support for this hypothesis raises questions either of the tenability of this assumption or its generality. The effects of songs with violent lyrics are likely more subtle and complex than predicted by the General Aggression Model (e.g., Anderson \& Bushman, 2002; Anderson, Carnagey, \& Eubanks, 2003). In conclusion, this study contributes to the body of literature related to media violence in that it investigated the effect of exposure to a song with violent lyrics, as well as provocation, on the actual behavior of interpersonal aggression. 
APPENDIX A

Peer Review Study Informed Consent 


\section{University of Wisconsin, Oshkosh \\ Informed Consent}

\section{Peer Review Study}

The Department of Psychology supports the practice of protecting human participants in research. The following information is provided so that you can decide whether you wish to participate in the present study. Your participation is solicited but is strictly voluntary. We assure you that your name and responses will remain confidential.

In this study you will be asked to write a brief essay on an assigned topic. You will receive feedback for your essay and then you will provide feedback on another essay by answering questionnaires. After receiving feedback you may be asked to write a second essay.

If you agree to participate, you will be free to withdraw at any time and will still receive credit for your participation. If you decide not to participate in this study, please let the researcher know and he or she will excuse you from the study. You do not need to tell the researcher your reasons for choosing not to participate. If you do decide to withdraw from the study, any information collected from you up to that point will then be destroyed.

All results will be recorded anonymously. You will not meet any other participants in this study, and your identity will not be revealed to any other participants. We will not release information about you in any way or form that could identify you.

Once the study is completed, we would be glad to provide you with the results. In the meantime, if you have any questions, please ask us or contact:

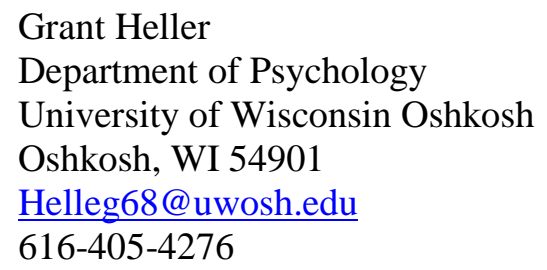

If you have any complaints about your treatment as a participant in this study, please call or write:

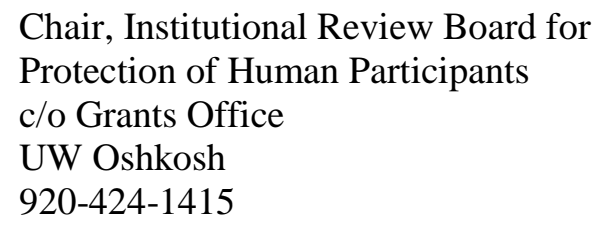

Although the chairperson may ask for your name, all complaints are kept in confidence.

I have received an explanation of the study and agree to participate. I understand that my participation in this study is strictly voluntary, and that I may withdraw at any time. 
APPENDIX B

Peer Review Study Instructions 


\section{Peer Review Study}

Instructions

The study in which you are participating is aimed at revising a standard peer review process into a program specifically designed to improve the writing and critical thinking skills of incoming freshman at the University of Wisconsin-Oshkosh. The program, Peer Review Educational Process (P.R.E.P.), will be an optional 2-week writing workshop held before freshman orientation. P.R.E.P. is being developed by the Department of Psychology as a service to the university. Your participation will help in the development of this program by allowing the investigator to better determine how feedback from peers can be used to maximize educational benefits.

In this study you will be asked to write a short essay on an assigned topic. This entails writing a timed 10 minute essay in response to a brief statement. There are several possible topics on which you may be asked to write. Your assigned topic will appear at the top of the first page in the folder given to you by the research assistant. You may either endorse or refute this statement, but do your best to provide examples and/or relevant reasons to support and develop your views. Your essay will be rated on its organization, breadth of vocabulary, spelling and grammar, development of noteworthy ideas, and overall effectiveness.

Your essay will be reviewed by another participant who will rate your response with a Feedback Form. This participant will be working in an adjacent room, but the starting times in this study have been staggered so that the two of you will never meet. This is so you may freely express your opinions in the essay and feedback tasks without worry of your identity being revealed. Do not write your name on your essay or any of the other questionnaires you will be asked to fill out.

After receiving your feedback you will be asked to rate an essay written by the other participant using the same Feedback Form. The essay you rate may be in response to a different statement than the one you received. You will then be asked to fill out a brief questionnaire on your reactions to the feedback you received. At this point you will be asked to write a second essay, which will be critiqued by an independent reviewer to determine the effects of the peer review process. If you have any questions about the study please ask the research assistant now. 
APPENDIX C

Essay Task 


\section{Essay Task}

Please present your views on the issue below, using relevant examples and/or reasons for support. You will have 10 minutes to complete this essay.

Although the United States is one of the richest countries in the world, healthcare has become so expensive that many Americans are unable to afford medical insurance coverage or care. One proposed solution to this problem has been for the U.S. federal government to provide universal healthcare for all citizens. However, the cost of such a program would be extremely expensive. As taxes would have to be greatly increased to cover these expenses, universal healthcare would be an unpractical solution to America's medical insurance problem. 
APPENDIX D

Music Pilot Study Informed Consent 


\section{UNIVERSITY OF WISCONSIN-OSHKOSH INFORMED CONSENT FORM MUSIC PILOT STUDY}

Graduate student Samantha Beckett of the department of psychology at the University of Wisconsin Oshkosh is conducting a pilot test to help select music for a future study on lyrical content of songs. I would appreciate your participation, as I believe it will allow for the design of a better experiment.

For this study you will listen to one song and then complete a brief music questionnaire. The questionnaire will not be labeled with any identifying information. It may take you up to 10 minutes to complete this study. Other than potentially listening to explicit lyrics it is not anticipated that you will be presented with any medical or social risks.

Your participation in this study is completely voluntary - you do not have to participate and you can stop at any time. If you refuse to participate now, or withdraw from the study later, it will have no effect on any regular services or benefits available to you at the University of Wisconsin Oshkosh.

If you should have any questions about this study, please contact:

\section{Samantha Beckett \\ Department of Psychology \\ University of Wisconsin Oshkosh \\ (920) 424-0781}

If you have any complaints about your treatment as a participant in this study, please call or write:

Chair, Institutional Review Board for

Protection of Human Participants

c/o Grants Office

(920) 424-1415

Although the chairperson may ask for your name, all complaints are kept in confidence.

print name

signature

date 
APPENDIX E

Music Pilot Study Instructions 


\section{Music Pilot Study}

The goal of this brief pilot study is to select music for a future study investigating preference for different musical genres, lyrical content, and overall song meaning by college majors. In order to create the best study possible, I am attempting to select songs that are enjoyable to students and that have understandable lyrics that are relevant to our research interests.

In this study you will be asked to listen attentively to one song on the provided Minidisc player. Please listen carefully to the musical content and the lyrics of the song, as you will very shortly be asked to rate these criteria. Once the song is over, please remove the Music Questionnaire sheet from your folder and answer all of the questions to the best of you ability. Your help is very much appreciated, as it allows for the design of a better study!

Sincerely,

Samantha Beckett 
APPENDIX F

Music Questionnaire 


\section{MUSIC QUESTIONNAIRE}

\section{Instructions}

Please circle the number that best reflects your most accurate response for each question. Please answer all questions.

How would you rate your mood after listening to this song?

$\begin{array}{ccccc}\mathbf{1} & \mathbf{2} & \mathbf{3} & \mathbf{4} & \mathbf{5} \\ \begin{array}{c}\text { Very } \\ \text { Unpleasant }\end{array} & & \text { Neutral } & & \text { Very } \\ & & & & \text { Pleasant }\end{array}$

How excited did this song make you feel?

1

Not at all

Excited

How understandable were the lyrics of this song? $\stackrel{3}{\text { Moderately }}$

Excited
4

5

Very

Excited

4

$\mathbf{5}$
Very
Clear

4

5 High amount of Humor

How violent did the lyrics seem to you?

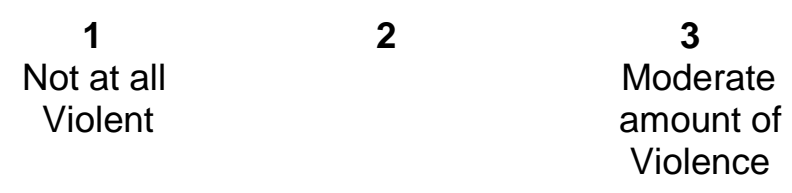

How happy did the lyrics seem to you?

\begin{tabular}{|c|}
\hline $\begin{array}{c}1 \\
\text { Very } \\
\text { Unhappy }\end{array}$ \\
\hline
\end{tabular}

4

5

Very Happy 
Music Questionnaire (cont.)

How much did you like the lyrics of this song?

$\begin{array}{ccccc}\mathbf{1} & \mathbf{2} & \mathbf{3} & \mathbf{4} & \mathbf{5} \\ \begin{array}{c}\text { Strongly } \\ \text { Dislike }\end{array} & & \text { Neutral } & & \begin{array}{c}\text { Strongly } \\ \text { Like }\end{array}\end{array}$

How much did you like the musical aspects of this song?

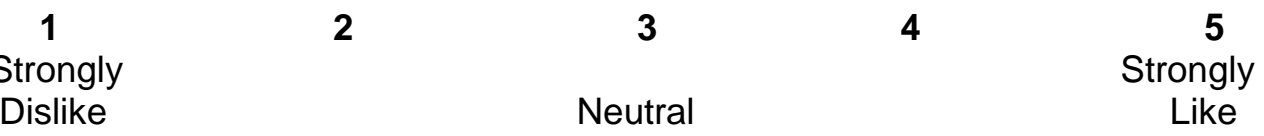

On average, how often do you choose to listen to music similar to this song?

$\begin{array}{llccl}\mathbf{1} & \mathbf{2} & \mathbf{3} & \mathbf{4} & \mathbf{5} \\ \text { Never } & \text { Yearly } & \text { Monthly } & \text { Weekly } & \text { Daily }\end{array}$


APPENDIX G

Audio Instructions 


\section{Audio Instructions}

$<$ In female voice > "Thank you for participating in this pilot study. Please listen closely to the music and lyrics in the following song. When the track has finished, fill out the enclosed music questionnaire. When you have completed the questionnaire please return this form and your informed consent to the experimenter. Thank you again." 
APPENDIX H

Lyric Conditions 
Lyric Conditions

$\underline{\text { Violent }}$

Rap

50 Cent (2003a) "Many Men"

Aggressive Primes: 27

Hard Rock

Tool (1992b) "Jerk-Off"

Aggressive Primes: 10

Pop/Rock

The Police (1990b) "Murder by Numbers"

Aggressive Primes: 13

$\underline{\text { Non-Violent }}$

Rap

50 Cent (2003b) “21 Questions"

Aggressive Primes: 1

Hard Rock

Tool (1990a) "Cold and Ugly"

Aggressive Primes: 0

Pop/Rock

The Police (1990a) "Every Little Thing She Does is Magic"

Aggressive Primes: 0 
APPENDIX I

Song Lyrics 


\section{Lyric Condition: Non-Violent Rap}

50 Cent (2003b)

"21 Questions"

[50 Cent]

New York City!

You are now rapping....with 50 Cent

You gotta love it...

I just wanna chill and twist a lot

Catch suns in my 7-45

You drive me crazy shorty

I need to see you and feel you next to me

I provide everything you need and I

Like your smile I don't wanna see you cry

Got some questions that I got to ask and I

Hope you can come up with the answers babe

[Nate Dogg]

Girl...It's easy to love me now

Would you love me if I was down and out?

Would you still have love for me?

Girl...It's easy to love me now

Would you love me if I was down and out?

Would you still have love for me?

Girl...

[50 Cent]

If I feel off tomorrow would you still love me?

If I didn't smell so good would you still hug me?

If I got locked up and sentenced to a quarter century,

Could I count on you to be there to support me mentally?

If I went back to a hoopty from a Benz, would you poof and disappear like some of my friends?

If I was hit and I was hurt would you be by my side?

If it was time to put in work would you be down to ride?

I'd get out and peel a nigga cap and chill and drive

I'm asking questions to find out how you feel inside

If I ain't rap 'cause I flipped burgers at Burger King

would you be ashamed to tell your friends you feelin' me?

And in bed if I used to my tongue, would you like that?

If I wrote you a love letter would you write back?

Now we can have a lil' drink you know a nightcap

And we could go do what you like, I know you like that 
[Nate Dogg]

Girl...It's easy to love me now

Would you love me if I was down and out?

Would you still have love for me?

Girl...It's easy to love me now (Woo!)

Would you love me if I was down and out?

Would you still have love for me?

Girl...

\section{[50 Cent]}

Now would you leave me if you're father found out I was thuggin'?

Do you believe me when I tell you, you the one I'm loving?

Are you mad 'cause I'm asking you 21 questions?

Are you my soulmate? 'Cause if so, girl you a blessing

Do you trust me enough, to tell me your dreams?

I'm staring at ya' trying to figure how you got in them jeans

If I was down would you say things to make me smile?

I treat you how you want to be treated just teach me how

If I was with some other chick and someone happened to see?

And when you asked me about it I said it wasn't me

Would you believe me? Or up and leave me?

How deep is our bond if that's all it takes for you to be gone?

We only human girl we make mistakes, to make it up I do whatever it take

I love you like a fat kid love cake

You know my style I say anything to make you smile

[Nate Dogg]

Girl...It's easy to love me now

Would you love me if I was down and out?

Would you still have love for me?

Girl...It's easy to love me now

Would you love me if I was down and out?

Would you still have love for me?

Girl...

Could you love me in a Bentley?

Could you love me on a bus?

I'll ask 21 questions, and they all about us

Could you love me in the bedroom?

Could you love me on a bus?

I'll ask 21 questions, and they all about us 


\section{Lyric Condition: Violent Rap}

50 Cent (2003a)

"Many Men"

Many men, wish death upon me

Blood in my eye dawg and I can't see

I'm trying to be what I'm destined to be

And niggas trying to take my life away

I put a hole in a nigga for fucking with me

My back on the wall, now you gonna see

Better watch how you talk, when you talk about me

'Cause I'll come and take your life away

Many men, many, many, many, many men

Wish death upon me

Lord I don't cry no more

Don't look to the sky no more

Have mercy on me

Now these pussy niggas putting money on my head

Go on and get your refund motherfucker, I ain't dead

I'm the diamond in the dirt, that ain't been found

I'm the underground king and I ain't been crowned

When I rhyme, something special happen every time

I'm the greatest, something like Ali in his prime

I walk the block with the bundles

I've been knocked on the humble

Swing the ax when I rumble

Show your ass what my gun do

Got a temper nigga, go'head, lose your head

Turn your back on me, get clapped and lose your legs

I walk around gun on my waist, chip on my shoulder

Till I bust a clip in your face, pussy, this beef ain't over

[chorus]

Many men, many, many, many, many men

Wish death upon me

Lord I don't cry no more

Don't look to the sky no more

Have mercy on me

Have mercy on my soul

Somewhere my heart turned cold

Have mercy on many men 
Many, many, many, many men

Wish death upon me

Sunny days wouldn't be special, if it wasn't for rain

Joy wouldn't feel so good, if it wasn't for pain

Death gotta be easy, 'cause life is hard

It'll leave you physically, mentally, and emotionally scarred

This if for my niggas on the block, twisting trees and cigars

For the niggas on lock, doing life behind bars

I don't see only god can judge me, 'cause I see things clear

Quick these crackers will give my black ass a hundred years

I'm like Paulie in Goodfellas, you can call me the Don Like Malcolm by any means, with my gun in my palm Slim switched sides on me, let niggas ride on me I thought we was cool, why you want me to die homie?

[chorus]

Every night I talk to god, but he don't say nothing back I know he protecting me, but I still stay with my gat In my nightmares, niggas keep pulling techs on me Psych says some bitch dumb, put a hex on me The feds didn't know much, when Pac got shot I got a kite from the pens that told me, Tuck got knocked I ain't gonna spell it out for you motherfuckers all the time Are you illiterate nigga? You can't read between the lines In the bible it says, what goes around, comes around Almost shot me, three weeks later he got shot down Now it's clear that I'm here, for a real reason 'Cause he got hit like I got hit, but he ain't fucking breathing [chorus] 


\author{
Lyric Condition: Non-Violent Pop/Rock \\ The Police (1990a) \\ "Every Little Thing She Does is Magic"
}

Though I've tried before to tell her

Of the feelings I have for her in my heart

Every time that I come near her

I just lose my nerve

As I've done from the start

Every little thing she does is magic

Everything she do just turns me on

Even though my life before was tragic

Now I know my love for her goes on

Do I have to tell the story

Of a thousand rainy days since we first met

It's a big enough umbrella

But it's always me that ends up getting wet

Every little thing she does is magic

Everything she do just turns me on

Even though my life before was tragic

Now I know my love for her goes on

I resolve to call her up a thousand times a day

And ask her if she'll marry me in some old fashioned way

But my silent fears have gripped me

Long before I reach the phone

Long before my tongue has tripped me

Must I always be alone?

Every little thing she does is magic

Everything she do just turns me on

Even though my life before was tragic

Now I know my love for her goes on

Every little thing she does is magic

Everything she do just turns me on

Even though my life before was tragic

Now I know my love for her goes on

Every little thing

Every little thing 


\section{Lyric Condition: Violent Pop/Rock}

The Police (1990b)

"Murder by Number"

Once that you've decided on a killing First you make a stone of your heart And if you find that your hands are still willing

Then you can turn a murder into art

There really isn't any need for bloodshed You just do it with a little more finesse If you can slip a tablet into someone's coffee

Then it avoids an awful lot of mess

It's murder by numbers one two three It's as easy to learn as your $\mathrm{ABC}$ Murder by numbers one two three It's as easy to learn as your ABC

Now if you have a taste for this experience

And you're flushed with your very first success

Then you must try a twosome or a threesome

And you'll find your conscience bothers you much less

Because murder is like anything you take to It's a habit-forming need for more and more
You can bump off every member of your family

And anybody else you find a bore

Because it's murder by numbers one two three

It's as easy to learn as your $\mathrm{ABC}$ Murder by numbers one two three It's as easy to learn as your $\mathrm{ABC}$

Now you can join the ranks of the illustrious

In history's great dark hall of fame All our greatest killers were industrious At least the ones that we all know by name

But you can reach the top of your profession

If you become the leader of the land For murder is the sport of the elected And you don't need to lift a finger of your hand

Because it's murder by numbers one two three It's as easy to learn as your $\mathrm{ABC}$ Murder by numbers one two three It's as easy to learn as your A B C D E 


\section{Lyric Condition: Non-Violent Hard Rock}

Tool (1992a)

"Cold and Ugly"

Underneath her skin and jewelry, Hidden in her words and eyes

Is a wall that's cold and ugly and she's scared as hell.

Trembling at the thought of feeling.

Wide awake and keeping distance.

Nothing seems to penetrate her.

'Cause she's scared as hell.

I am frightened too.

I am frightened.

Trembling at the thought of feeling.

Wide awake and keeping distance.

Nothing seems to penetrate her

'Cause she's scared as hell

I am frightened too.

I am frightened.

Wide awake and keeping distance from my soul.

Wide awake and keeping distance from my soul.

Save.

Underneath her skin and jewelry,

Hidden in her words and eyes

Is a wall that's cold and ugly and she's scared as hell.

Trembling at the thought of feeling.

Wide awake and keeping distance.

Nothing seems to penetrate her.

'Cause she's scared as hell.

I am frightened too.

I am frightened too.

I am scared like you.

I am frightened. 


\section{Lyric Condition: Violent Hard Rock}

\section{Tool (1992b) \\ "Jerk-Off"}

Someone told me once that there's a right and wrong, and that punishment would come to those who dare to cross the line. But it must not be true for jerk-offs like you.

Maybe it takes longer to catch a total asshole.

But I'm tired of waiting.

Maybe it's just bullshit and I should play GOD, and shoot you myself.

Someone told me once that there's a right and wrong, and that punishment would come to those who dare to cross the line. But it must not be true for jerk-offs like you. Maybe it takes longer to catch a total asshole.

But I'm tired of waiting.

Maybe it's just bullshit and I should play GOD, and shoot you myself!

Because I'm tired of waiting.

Consequences dictate our course of action and it doesn't matter what's right.

It's only wrong if you get caught.

If consequences dictate my course of action I should...

I should play GOD and just shoot you myself. I'm very tired of waiting.

Die!!!

Shoot it!...kick it!...fuck it!... shoot you in your fucking head!!! 
APPENDIX J

Feedback Form 


\section{Feedback Form}

Please review the essay you have received on the following criteria by circling the most appropriate response for each question. Use the blank space at the bottom of this sheet for any additional comments you wish to provide.

\section{1.) Organization}

$\begin{array}{ccccccc}1 & 2 & 3 & 4 & 5 & 6 & 7 \\ \text { Very } & & & \begin{array}{l}\text { Moderately } \\ \text { Organized }\end{array} & & & \begin{array}{r}\text { Very Well } \\ \text { Organized }\end{array}\end{array}$

\section{2.) Breadth of Vocabulary}

$\begin{array}{llccccc}1 & 2 & 3 & 4 & 5 & 6 & 7 \\ \text { Weak } & & & \text { Average } & & & \text { Strong } \\ \text { Vocab. } & & \text { Vocab. } & & & \text { Vocab. }\end{array}$

\section{3.) Spelling and Grammar}

$\begin{array}{ccccccc}1 & 2 & 3 & 4 & 5 & 6 & 7 \\ \text { Poor } & & & \text { Average } & & & \text { Excellent }\end{array}$

\section{4.) Development of Noteworthy Ideas}

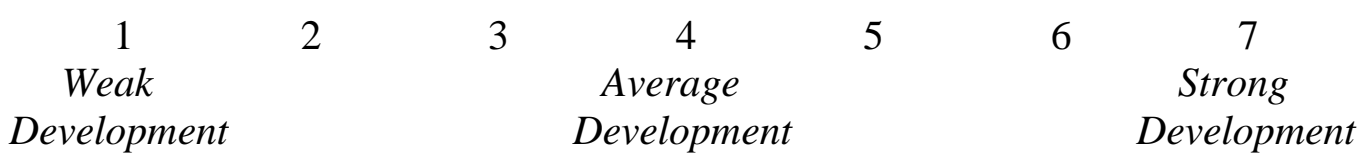

\section{5.) Overall Effectiveness of the Essay}

$\begin{array}{ccccccc}1 & 2 & 3 & 4 & 5 & 6 & 7 \\ \text { Very } & & \begin{array}{c}\text { Moderately } \\ \text { Effective }\end{array} & & & \text { Very } \\ \text { Eneffective } & & \text { Effective }\end{array}$

6.) Please use the space below to write in any additional comments. 
APPENDIX K

Essay in Female Handwriting 


\section{Essay Task}

Please present your views on the issue below, using relevant examples and/or reasons for support. You will have 10 minutes to complete this essay.

The number or recent hurricanes, tsunamis, floods, and other natural disasters suggest that global warming is a real and serious threat to our planet. Thus, the United States should set an example for the rest of the world by actively pursuing alternative forms of renewable energy.

$$
\text { Global warming is a serious issue }
$$
and I think that the recent hurricanes are proof that were messing up our environment. I don't know exactly how we can fix this problem, but someone needs to do something about it soon or else were all in trouble. The us is a pretly influential country so we should try to do our best to do something about the environment. That way we could be an example of sorts for all the other countrys out there. I think we need to work on new fuel/energy solutions, but we can't just let that totally mess up our economy. That could cause another recession and just screw things up even more for everyone. Reducing our use of oil is pretty important I think. Then we will be less dependent on foreign countries for oil. Wo will save a lot of money and less will probably wind up going to tersosists. Besides that we now eutting down all countries in South America now it would be good to switch over to something cheaper or even free like solar power or something. 
APPENDIX L

Essay in Male Handwriting 


\section{Essay Task}

Please present your views on the issue below, using relevant examples and/or reasons for support. You will have 10 minutes to complete this essay.

The number or recent hurricanes, tsunamis, floods, and other natural disasters suggest that global warming is a real and serious threat to our planet. Thus, the United States should set an example for the rest of the world by actively pursuing alternative forms of renewable energy.

$$
\text { Global warming is a serious issue and (2) thint }
$$
thyt the recont hinicanes are proof that weie massing us om enviromant, Qdonit browexactly hou we can fix thit problem but sonerne neade to Ao sonettan about it soon. or else weir all in tronble. She US is a pretty influentiol Country so we should try to do om heselto do pometing alobit the embiconnent. Jhat way we could be an example of sorts fir all she otted countrys ont shere. \& think we nead to work on new fral / energersolutions, but we cant jist

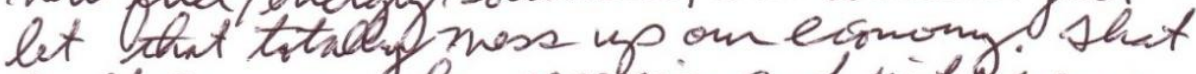
coned cause another recession and jist drem thing up even move for evergone. Redving our use of ail is pretty insontant? think. Than we wilt be las dependint on trieign Contiver for ail. We mill save a Cot of moneg and lese will probubly wind up going to

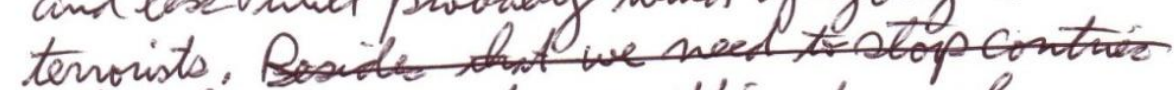
in Aouth Americe from ontting downith Aainfousto. Alar energy is so expousive now A would be good to suntch oven to sonetting clasaper or lven free libe solarporva orsomething. 
APPENDIX M

Positive Feedback in Female Handwriting 
Feedback Form

Please review the essay you have received on the following criteria by circling the most appropriate response for each question. Use the blank space at the bottom of this sheet for any additional comments you wish to provide.

\section{1.) Organization}

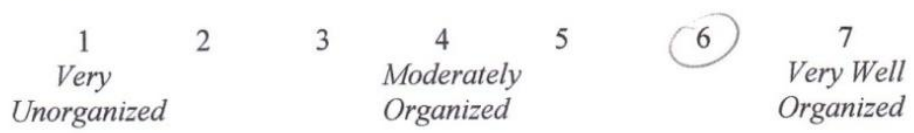

\section{2.) Breadth of Vocabulary}

$\begin{array}{lllccc}1 & 2 & 3 & 4 & 5 & \text { (6) } \\ \begin{array}{l}\text { Weak } \\ \text { Vocab. }\end{array} & & & \begin{array}{c}7 \\ \text { Vocab. }\end{array} & & \text { Strong } \\ \text { Vocab. }\end{array}$

\section{3.) Spelling and Grammar}

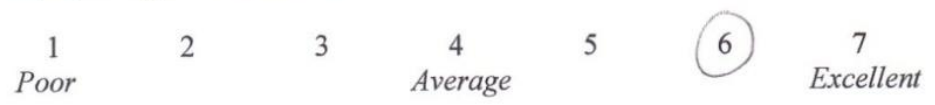

4.) Development of Noteworthy Ideas

$\begin{array}{ccccc}1 & 2 & 3 & 4 & 5\end{array}$

5.) Overall Effectiveness of the Essay

$\begin{array}{ccccccc}1 & 2 & 3 & 4 & 5 & 6 & \underbrace{\text { Efferately }}_{\begin{array}{c}7 \\ \text { Very } \\ \text { Ineffective }\end{array}} \\ \text { Effective }\end{array}$

6.) Please use the space below to write in any additional comments.

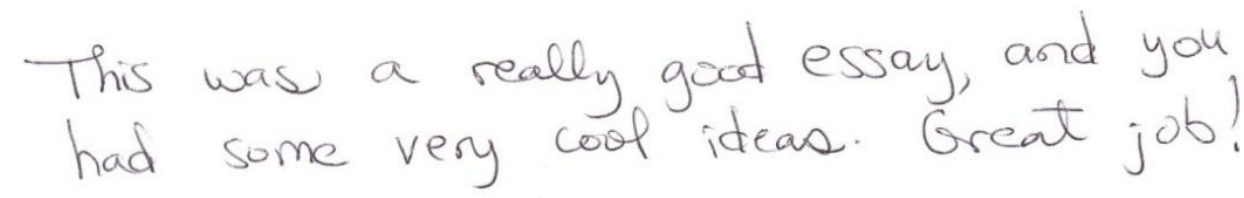


APPENDIX N

Insulting Negative Feedback in Female Handwriting 


\section{Feedback Form}

Please review the essay you have received on the following criteria by circling the most appropriate response for each question. Use the blank space at the bottom of this sheet for any additional comments you wish to provide.

1.) Organization

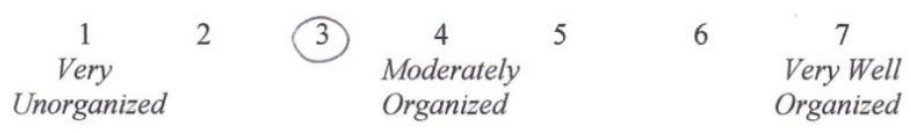

2.) Breadth of Vocabulary

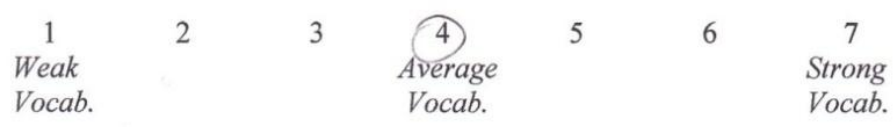

3.) Spelling and Grammar

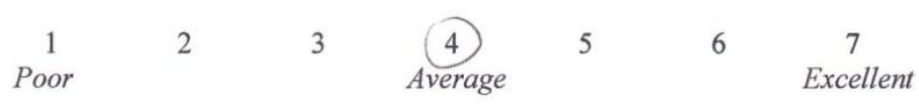

4.) Development of Noteworthy Ideas

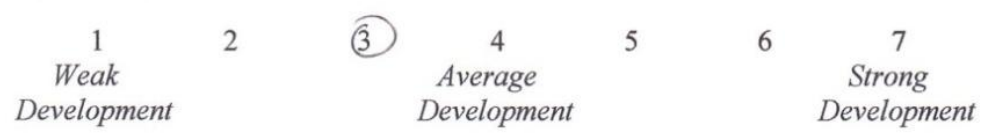

5.) Overall Effectiveness of the Essay

\begin{tabular}{|c|c|c|c|c|}
\hline $\begin{array}{c}1 \\
\text { Very } \\
\text { Ineffective }\end{array}$ & 3 & $\begin{array}{c}4 \\
\text { Moderately } \\
\text { Effective }\end{array}$ & 5 & 6 \\
\hline
\end{tabular}

6.) Please use the space below to write in any additional comments.

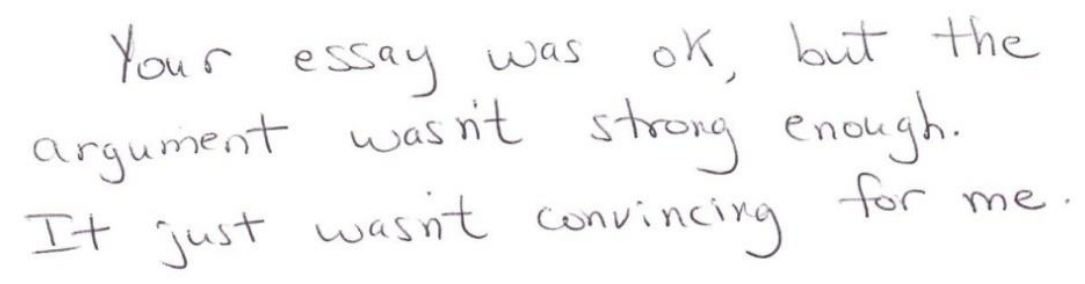


APPENDIX O

Positive Feedback in Male Handwriting 


\section{Feedback Form}

Please review the essay you have received on the following criteria by circling the most appropriate response for each question. Use the blank space at the bottom of this sheet for any additional comments you wish to provide.

\section{1.) Organization}

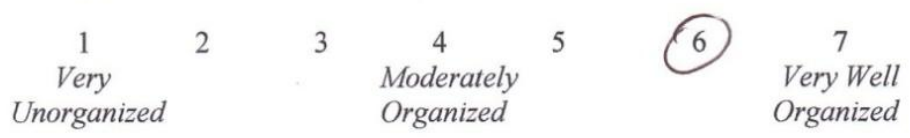

\section{2.) Breadth of Vocabulary}

$\begin{array}{lllcll}1 & 2 & 3 & 4 & 5 & \text { (6) } \\ \text { Weak } & \text { Vocab. } & 7 & 7 \\ \text { Vocab. } & & & \begin{array}{l}\text { Strong } \\ \text { Vocab. }\end{array}\end{array}$

\section{3.) Spelling and Grammar}

$\begin{array}{cccccc}1 & 2 & 3 & 4 & 5 & 6\end{array} \begin{gathered}7 \\ \text { Poor }\end{gathered}$

4.) Development of Noteworthy Ideas

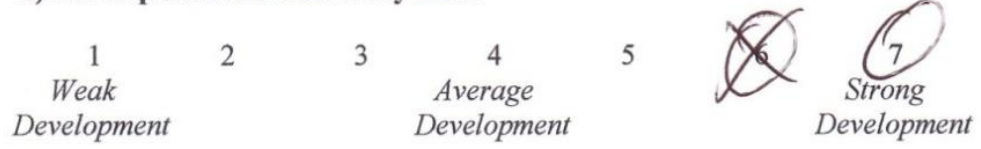

5.) Overall Effectiveness of the Essay

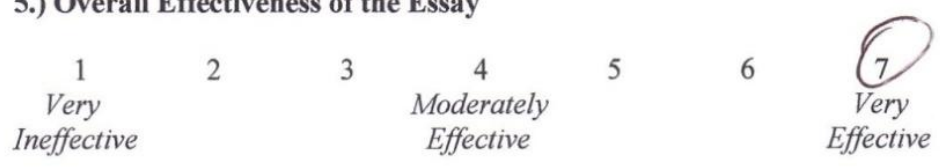

6.) Please use the space below to write in any additional comments.

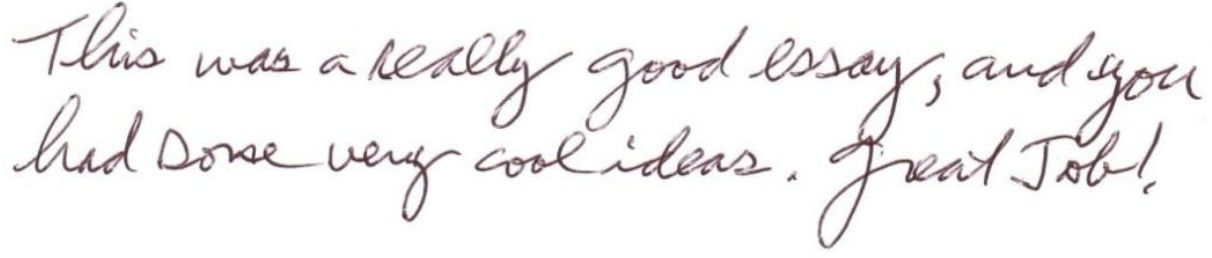




\section{APPENDIX P}

Insulting Negative Feedback in Male Handwriting 


\section{Feedback Form}

Please review the essay you have received on the following criteria by circling the most appropriate response for each question. Use the blank space at the bottom of this sheet for any additional comments you wish to provide.

\section{1.) Organization}

$\begin{array}{ccccc}1 & 2 & 5 & 6 & 7 \\ \begin{array}{c}\text { Very } \\ \text { Unorganized }\end{array} & \begin{array}{c}4 \\ \text { Moderately } \\ \text { Organized }\end{array} & 5 & & \begin{array}{c}7 \\ \text { Orgathell } \\ \text { Organized }\end{array}\end{array}$

2.) Breadth of Vocabulary

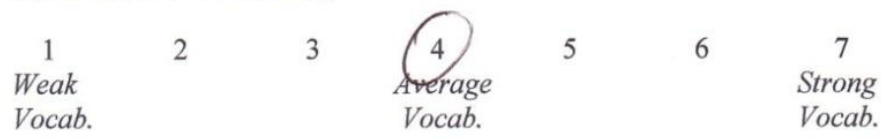

3.) Spelling and Grammar

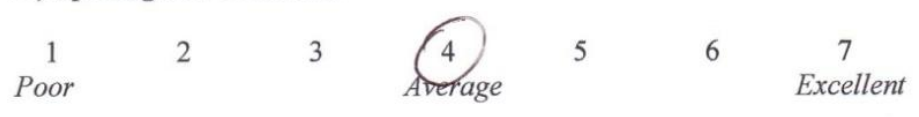

4.) Development of Noteworthy Ideas

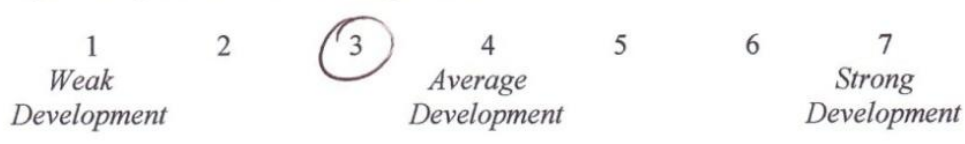

5.) Overall Effectiveness of the Essay

\begin{tabular}{|c|c|c|c|c|c|}
\hline $\begin{array}{c}1 \\
\text { Very } \\
\text { Ineffective }\end{array}$ & 3 & $\begin{array}{c}4 \\
\text { Moderately } \\
\text { Effective }\end{array}$ & 5 & 6 & $\begin{array}{c}7 \\
\text { Very } \\
\text { Effective }\end{array}$ \\
\hline
\end{tabular}

6.) Please use the space below to write in any additional comments.

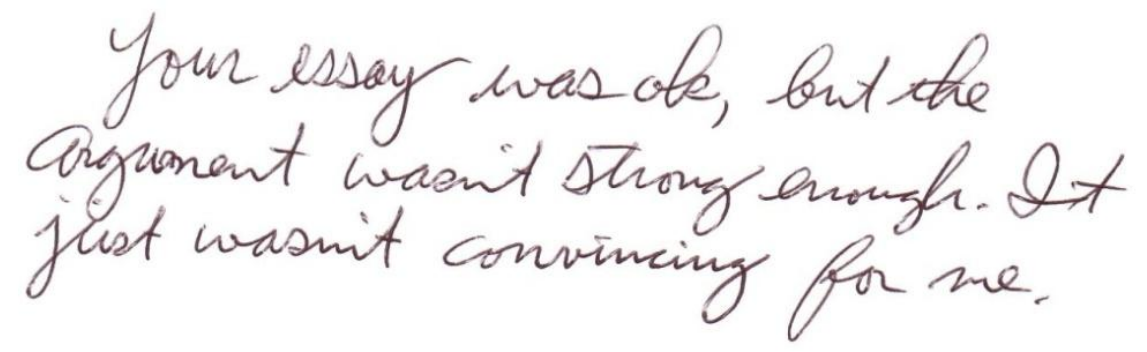


APPENDIX Q

Quality of Feedback Questionnaire 
Quality of Feedback Questionnaire

1.) Do you feel the other participant was fair in rating your essay?

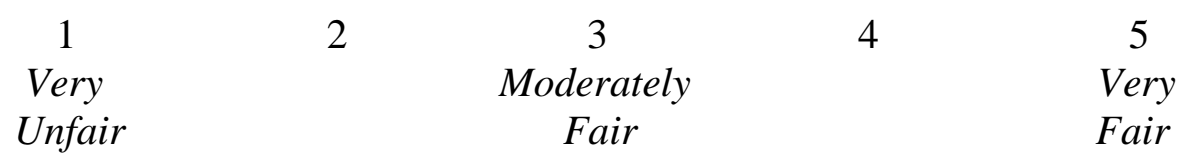

2.) How objective do you feel the other participant was in rating your essay?

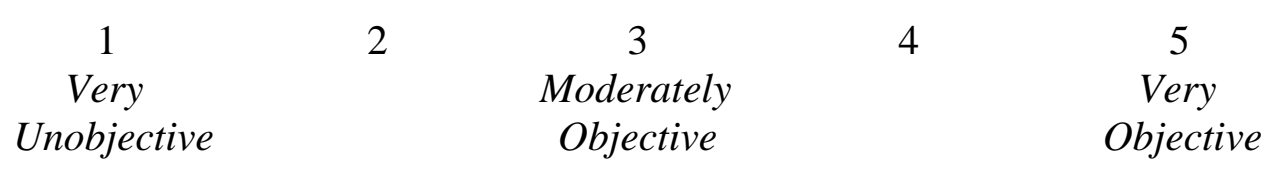

3.) Did the comments provide you with useful constructive criticism or advice on improving your essay?

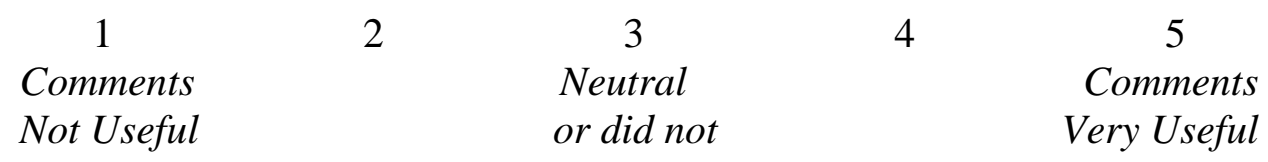

Receive Written Comments

4.) How competent do you feel the other participant is?

\begin{tabular}{|c|c|c|c|c|}
\hline 1 & 2 & 3 & 4 & 5 \\
\hline Very & & Moderately & & Very \\
\hline Incompetent & & Competent & & Competent \\
\hline
\end{tabular}

5.) How good did you feel after receiving feedback?

$\begin{array}{cccc}1 & 2 & 3 & 4 \\ \text { Not at all } & \text { Moderately } & & 5 \\ \text { Good } & \text { Good } & & \text { Good }\end{array}$

6.) How frustrated did you feel after receiving feedback?

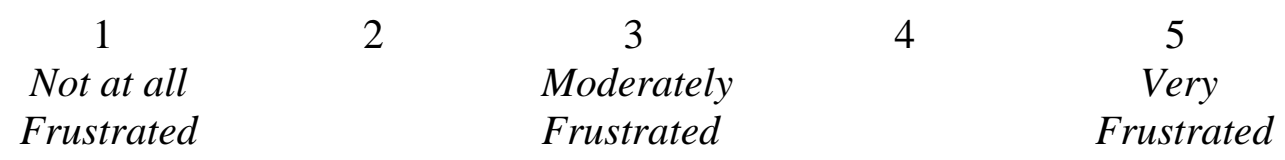


Quality of Feedback Questionnaire (cont.)

7.) How angry did you feel after receiving feedback?

$\begin{array}{cccc}1 & 2 & 3 & 4 \\ \text { Not at all } & \text { Moderately } & & 5 \\ \text { Angry } & \text { Angry } & & \text { Angry }\end{array}$

8.) Did you feel insulted by the feedback?

$\begin{array}{cccc}1 & 2 & 3 & 4 \\ \text { Not at all } & \text { Moderately } & & 5 \\ \text { Insulted } & & \text { Insulted } & \text { Insulted }\end{array}$

9.) How would you have rated the overall effectiveness of your essay?

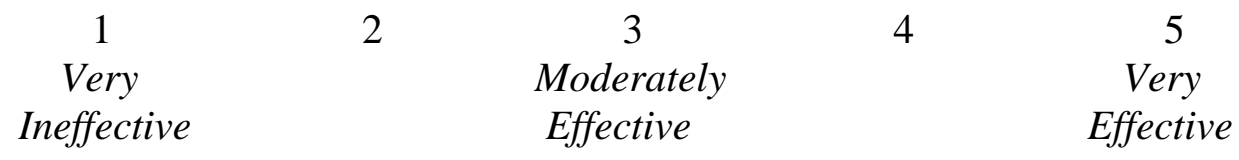

Please use the space below to write any additional comments about how you felt after receiving feedback on your essay. 
APPENDIX R

Tables 
Table R-1

Means and Standard Deviations for Items on the Music Questionnaire

\begin{tabular}{|c|c|c|}
\hline \multirow[b]{2}{*}{ Lyrics } & \multicolumn{2}{|c|}{ Feedback } \\
\hline & Negative & Positive \\
\hline \multicolumn{3}{|l|}{ Mood after listening } \\
\hline Violent & $2.750(1.035)$ & $2.500(1.168)$ \\
\hline Non-violent & $3.750(0.965)$ & $3.800(1.033)$ \\
\hline \multicolumn{3}{|c|}{ Excitement after listening } \\
\hline Violent & $1.875(0.991)$ & $2.000(0.853)$ \\
\hline Non-violent & $2.833(1.267)$ & $2.600(1.075)$ \\
\hline \multicolumn{3}{|l|}{ Clarity of lyrics } \\
\hline Violent & $3.500(1.195)$ & $3.500(0.905)$ \\
\hline Non-violent & $3.500(1.087)$ & $4.000(1.155)$ \\
\hline \multicolumn{3}{|l|}{ Humor in lyrics } \\
\hline Violent & $1.875(1.356)$ & $1.750(1.055)$ \\
\hline Non-violent & $2.000(1.348)$ & $2.200(1.135)$ \\
\hline \multicolumn{3}{|l|}{ Violence in lyrics } \\
\hline Violent & $3.375(1.685)$ & $3.917(1.084)$ \\
\hline Non-violent & $1.750(1.215)$ & $1.700(1.059)$ \\
\hline \multicolumn{3}{|l|}{ Happiness of lyrics } \\
\hline Violent & $1.500(0.756)$ & $1.667(0.651)$ \\
\hline Non-violent & $3.167(1.267)$ & $3.100(1.595)$ \\
\hline \multicolumn{3}{|l|}{ Like lyrics } \\
\hline Violent & $2.000(0.926)$ & $2.167(1.193)$ \\
\hline Non-violent & $3.333(1.154)$ & $3.300(1.252)$ \\
\hline \multicolumn{3}{|l|}{ Like musical aspects } \\
\hline Violent & $3.500(1.151)$ & $3.417(1.311)$ \\
\hline Non-violent & $3.417(1.165)$ & $3.600(1.265)$ \\
\hline
\end{tabular}

(Table R-1 continues) 
Feedback

\begin{tabular}{|c|c|c|}
\hline \multirow{2}{*}{ Lyrics } & \multicolumn{2}{|c|}{ Feedback } \\
\hline & Negative & Positive \\
\hline \multicolumn{3}{|c|}{ Frequency of listening } \\
\hline Violent & $2.375(1.506)$ & $2.583(1.621)$ \\
\hline Non-violent & $2.917(1.444)$ & $3.100(1.524)$ \\
\hline \multicolumn{3}{|c|}{$\begin{array}{l}\text { Note: } n=42(8 \text { negative feedback/violent lyrics, } 12 \text { negative feedback/non-violent lyrics, } \\
12 \text { positive feedback/violent lyrics, } 10 \text { positive feedback/non-violent lyrics }) ; \text { Standard } \\
\text { deviations are in parentheses; Mood }(1=\text { very unpleasant, } 5=\text { very pleasant }) \text {, Excitement } \\
(1=\text { not at all excited, } 5=\text { very excited }) \text {, Clarity }(1=\text { very unclear, } 5=\text { very clear }) \text {, Humor } \\
(1=\text { not at all humorous, } 5=\text { high amount of humor }), \text { Violence }(1=\text { not at all violent, } 5= \\
\text { high amount of violence }), \text { Happiness }(1=\text { very unhappy, } 5=\text { very happy }) \text {, Like lyrics }(1= \\
\text { strongly dislike, } 5=\text { strongly like }), \text { Like music }(1=\text { strongly dislike, } 5=\text { strongly like }), \\
\text { Frequency of listening }(1=\text { never, } 5=\text { daily). }\end{array}$} \\
\hline
\end{tabular}


Table R-2

Means and Standard Deviations for Items on the Quality of Feedback Questionnaire

\begin{tabular}{|c|c|c|}
\hline \multirow[b]{2}{*}{ Lyrics } & \multicolumn{2}{|c|}{ Feedback } \\
\hline & Negative & Positive \\
\hline \multicolumn{3}{|c|}{ Fairness of ratings received } \\
\hline Violent & $3.750(1.165)$ & $4.250(1.215)$ \\
\hline Non-violent & $3.250(0.866)$ & $4.500(0.850)$ \\
\hline \multicolumn{3}{|c|}{ Objectiveness of ratings received } \\
\hline Violent & $3.250(1.165)$ & $3.583(1.165)$ \\
\hline Non-violent & $3.500(1.000)$ & $3.500(0.972)$ \\
\hline \multicolumn{3}{|c|}{ Usefulness of comments received } \\
\hline Violent & $3.125(1.126)$ & $2.917(1.240)$ \\
\hline Non-violent & $2.875(1.131)$ & $2.500(1.650)$ \\
\hline \multicolumn{3}{|c|}{ Competence of other participant } \\
\hline Violent & $3.500(0.756)$ & $3.333(0.888)$ \\
\hline Non-violent & $3.000(0.603)$ & $3.800(0.788)$ \\
\hline \multicolumn{3}{|c|}{ How good did you feel after receiving feedback? } \\
\hline Violent & $3.250(1.035)$ & $4.250(1.055)$ \\
\hline Non-violent & $2.667(0.985)$ & $4.500(0.707)$ \\
\hline \multicolumn{3}{|c|}{ Frustration after receiving feedback } \\
\hline Violent & $1.625(0.744)$ & $1.417(1.165)$ \\
\hline Non-violent & $2.667(1.155)$ & $1.300(0.483)$ \\
\hline \multicolumn{3}{|l|}{$\begin{array}{l}\text { Anger after receiving } \\
\text { feedback }\end{array}$} \\
\hline Violent & $1.500(0.756)$ & $1.083(0.289)$ \\
\hline Non-violent & $1.833(1.030)$ & $1.000(0.000)$ \\
\hline \multicolumn{3}{|c|}{ Insulted from feedback } \\
\hline Violent & $1.500(0.756)$ & $1.333(0.651)$ \\
\hline Non-violent & $2.167(1.115)$ & $1.000(0.000)$ \\
\hline
\end{tabular}

(Table R-2 continues) 
Feedback

Lyrics

Negative Positive

Self rating for effectiveness of own

essay

Violent

Non-violent

$2.583(0.900) \quad 3.300(1.059)$

Negative affectivity index

Violent

$1.400(0.607)$

Non-violent

$2.500(0.898)$

$1.200(0.230)$

Note: $n=42$ (8 negative feedback/violent lyrics, 12 negative feedback/non-violent lyrics, 12 positive feedback/violent lyrics, 10 positive feedback/non-violent lyrics); Standard deviations are in parentheses; Fairness $(1=$ very unfair, 5 = very fair $)$, Objectiveness $(1=$ very unobjective, 5 = very objective $)$, Usefulness of comments $(1=$ comments not useful, $5=$ comments very useful $)$, Competence of other participant $(1=$ very incompetent, $5=$ very competent), How good did you feel? $(1=$ not at all good, $5=$ very good $)$, Frustration $(1=$ not at all frustrated, $5=$ very frustrated $)$, Anger $(1=$ not at all angry, $5=$ very

angry), Insult ( $1=$ not at all insulted, $5=$ very insulted $)$, Self rating for effectiveness of own essay ( 1 = very ineffective, $5=$ very effective $)$. 
Table R-3

Means and Standard Deviations for Items on the Feedback Form

Feedback

Lyrics

Negative

Positive

Organization

Violent

Non-violent

$4.500(0.756) \quad 5.000(1.348)$

$3.667(1.073) \quad 5.200(1.229)$

Breadth of vocabulary

Violent

$3.500(0.756) \quad 4.583(1.240)$

Non-violent

$3.250(1.055) \quad 4.700(1.567)$

Spelling and grammar

Violent

$4.500(0.926) \quad 5.333(0.888)$

Non-violent

$3.583(0.793) \quad 5.700(1.567)$

Development of noteworthy ideas

Violent

$4.000(1.069) \quad 5.333(1.435)$

Non-violent

$3.500(1.087) \quad 5.400(2.011)$

Overall effectiveness of

essay

Violent

$3.875(1.246) \quad 5.250(0.866)$

Non-violent

$2.958(0.753) \quad 5.300(2.163)$

Mean of feedback ratings

Violent

$4.075(0.701) \quad 5.100(1.004)$

Non-violent

$3.392(0.647) \quad 5.260(1.558)$

Note: $n=42$ (8 negative feedback/violent lyrics, 12 negative feedback/non-violent lyrics, 12 positive feedback/violent lyrics, 10 positive feedback/non-violent lyrics); Standard deviations are in parentheses; Organization $(1=$ very unorganized, $7=$ very well organized $)$, Vocabulary $(1=$ weak vocab., 7 = strong vocab. $)$, Spelling and grammar $(1=$ poor, 7 = excellent $)$, Development $(1=$ weak development, $7=$ strong development $)$, Overall effectiveness $(1=$ very ineffective, $7=$ very effective $)$. 
APPENDIX S

Figures 


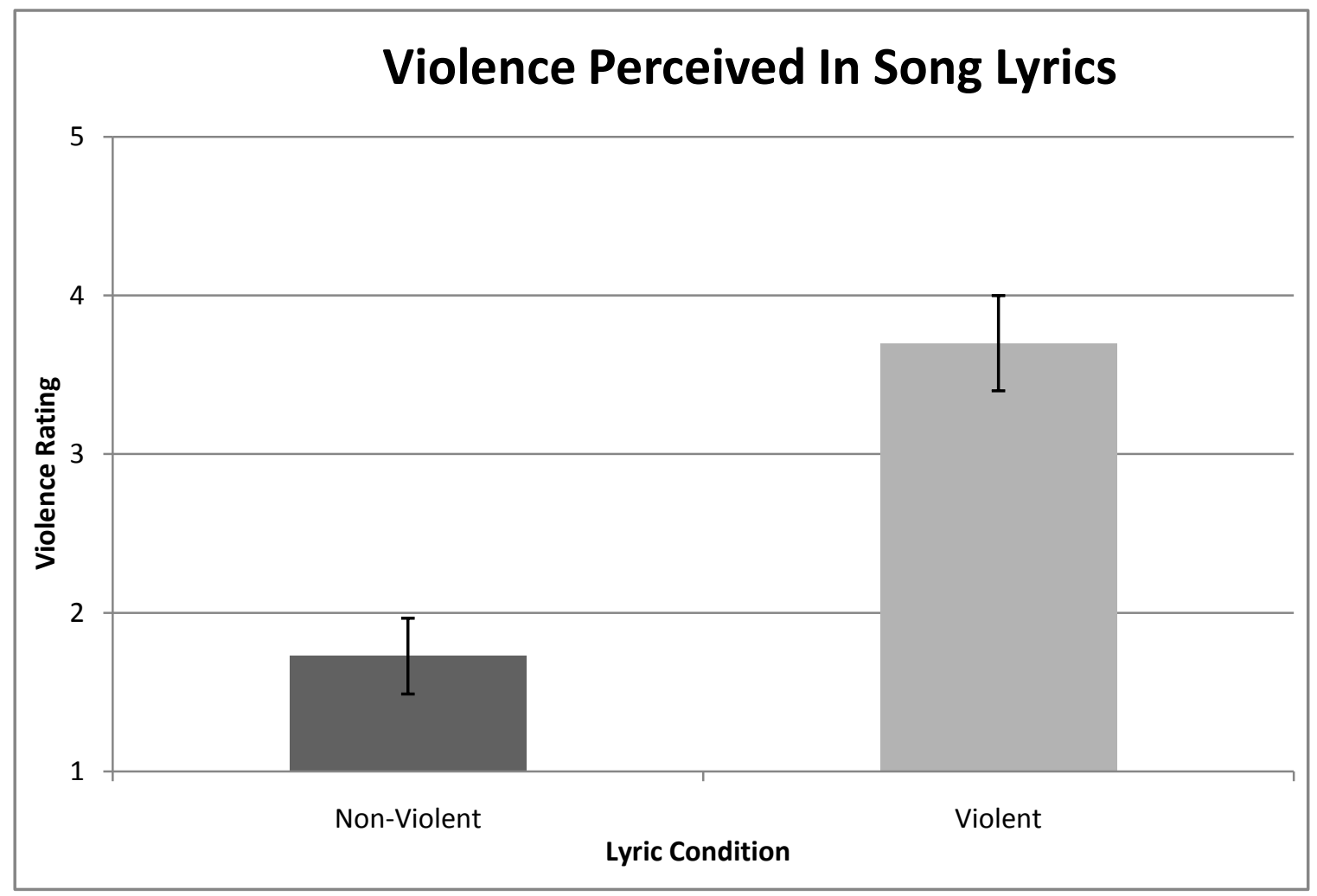

Condition Assignment

\begin{tabular}{|c|r|r|r|r|}
\hline \multicolumn{2}{|c|}{} & \multicolumn{2}{c|}{ Feedback } & \multicolumn{1}{c|}{ Total } \\
\cline { 3 - 5 } \multicolumn{2}{|c|}{} & Negative & Positive & \\
\hline \multirow{2}{*}{ Lyrics } & Violent & 8 & 12 & 20 \\
\cline { 2 - 5 } & NonViolent & 12 & 10 & 22 \\
\hline Total & & 20 & 22 & 42 \\
\hline
\end{tabular}

Figure S-1. Violence perceived in song lyrics. 


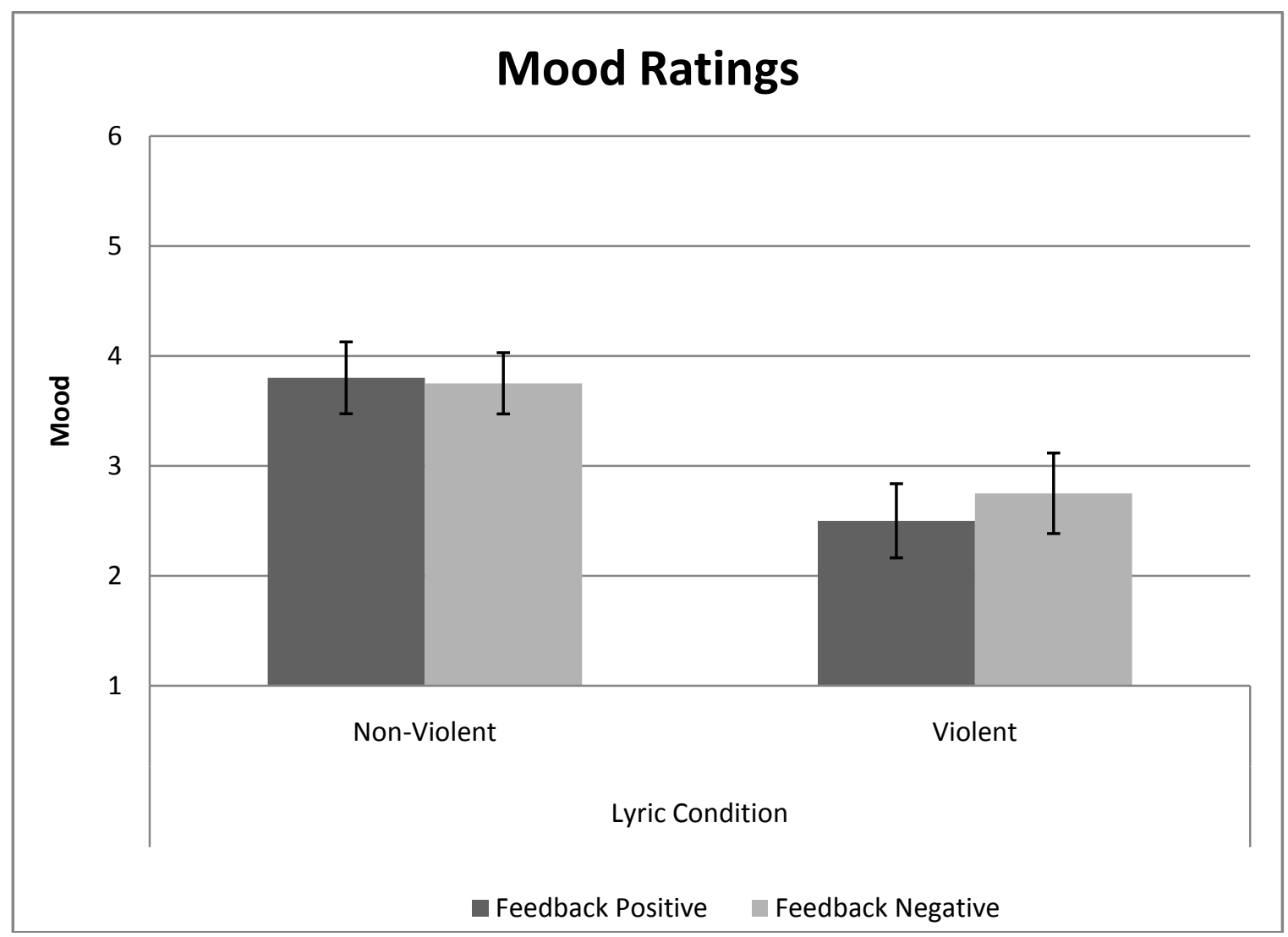

Condition Assignment

\begin{tabular}{|c|r|r|r|r|}
\hline \multicolumn{2}{|c|}{} & \multicolumn{2}{c|}{ Feedback } & \multicolumn{1}{c|}{ Total } \\
\cline { 3 - 5 } \multicolumn{2}{|c|}{} & Negative & Positive & \\
\hline \multirow{2}{*}{ Lyrics } & Violent & 8 & 12 & 20 \\
\cline { 2 - 5 } & NonViolent & 12 & 10 & 22 \\
\hline Total & & 20 & 22 & 42 \\
\hline
\end{tabular}

Figure S-2. Mood ratings. 


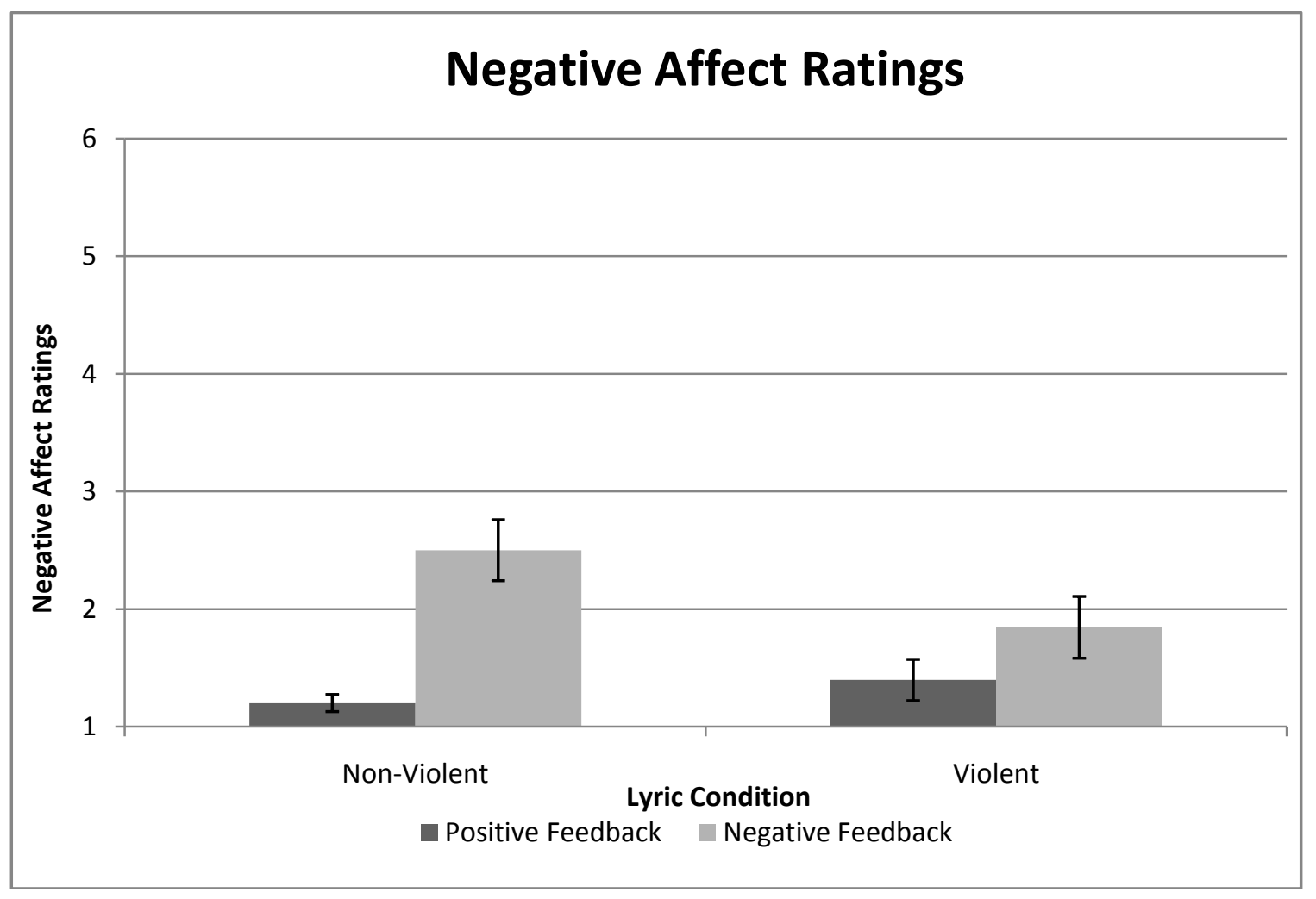

Condition Assignment

\begin{tabular}{|c|r|r|r|r|}
\hline \multicolumn{2}{|c|}{} & \multicolumn{2}{|c|}{ Feedback } & \multicolumn{1}{c|}{ Total } \\
\cline { 3 - 5 } \multicolumn{2}{|c|}{} & Negative & Positive & \\
\hline \multirow{2}{*}{ Lyrics } & Violent & 8 & 12 & 20 \\
\cline { 2 - 5 } & NonViolent & 12 & 10 & 22 \\
\hline Total & & 20 & 22 & 42 \\
\hline
\end{tabular}

Figure S-3.Negative affect ratings. 


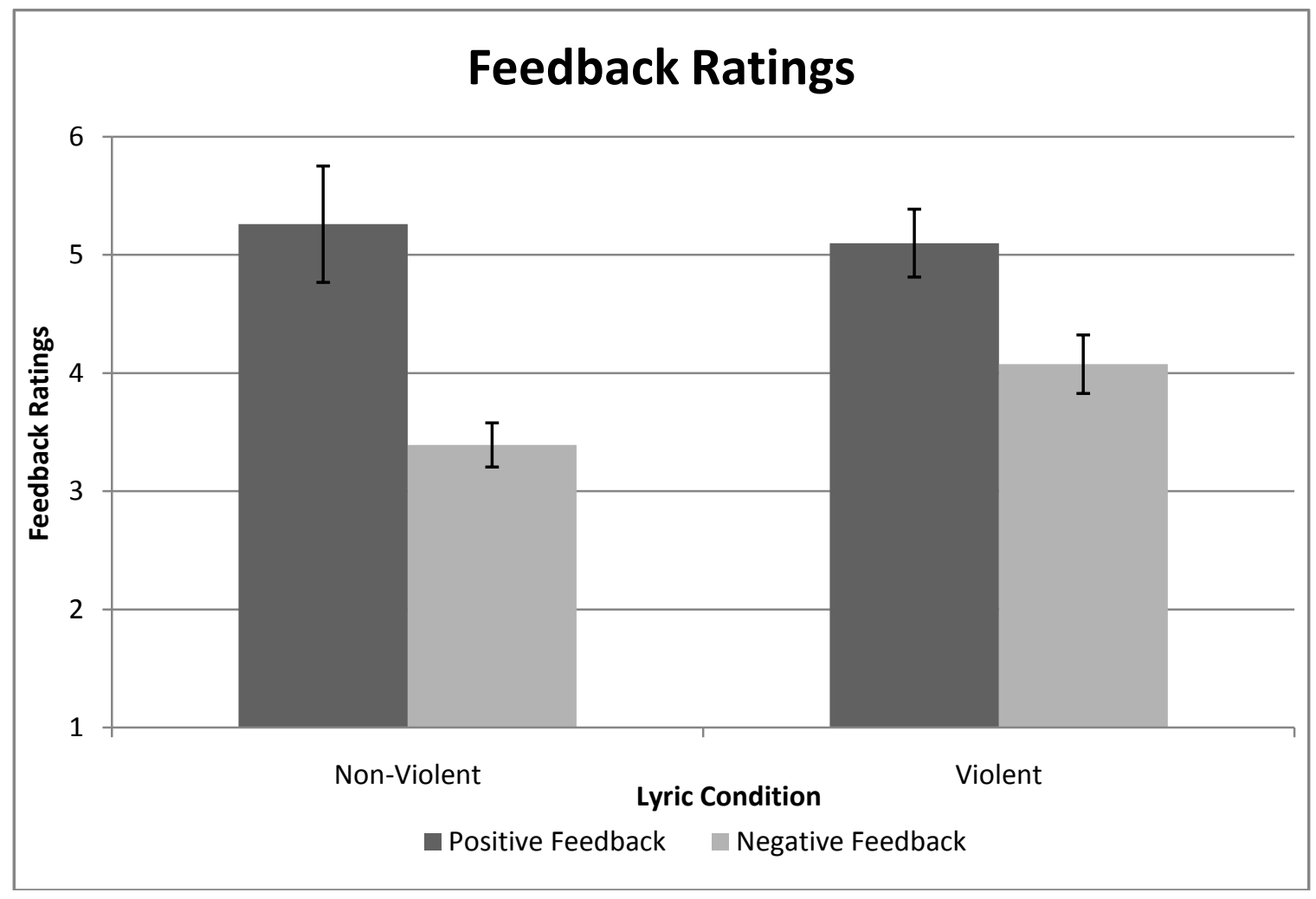

Condition Assignment

\begin{tabular}{|c|c|c|c|c|}
\hline & \multicolumn{2}{|c|}{ Feedback } & \multirow{3}{*}{$\begin{array}{r}\text { Total } \\
20 \\
\end{array}$} \\
\hline & & Negative & Positive & \\
\hline \multirow[t]{2}{*}{ Lyrics } & Violent & 8 & 12 & \\
\hline & NonViolent & 12 & 10 & 22 \\
\hline Total & & 20 & 22 & 42 \\
\hline
\end{tabular}

Figure $S$-4. Feedback ratings. 


\section{REFERENCES}

American Psychological Association. (1993). Violence and youth: Psychology's response. Washington, DC: APA.

Anderson, C. A., \& Anderson, D. C. (1984). Ambient temperature and violent crime: Tests of the linear and curvilinear hypotheses. Journal of Personality and Social Psychology, 46(1), 91-97.

Anderson, C. A., Berkowitz, L., Donnerstein, E., Huesmann, L. R., Johnson, J. D., Linz, D., Malamuth, N. M., \& Wartela, E. (2003). The influence of media violence on youth. Psychological Science in the Public Interest, 4, 81-110.

Anderson, C. A., \& Bushman, B. J. (2002). Human aggression. Annual Review of Psychology, 53, 27-51.

Anderson, C. A., Carnagey, N. L., \& Eubanks, J. (2003). Exposure to violent media: the effects of songs with violent lyrics on aggressive thoughts and feelings. Journal of Personality and Social Psychology, 84, 960-971.

Anderson, C. A., \& Dill, K. E. (2000). Video games and aggressive thoughts, feelings, and behavior in the laboratory and life. Journal of Personality and Social Psychology, 78, 772-790.

Azrin, N. H. (1967, May). Pain and aggression. Psychology Today, 1, 27-33.

Bandura, A. (1973). Aggression: A social learning analysis. Englewood Cliffs, NJ: Prentice-Hall.

Bandura, A. (1978). Social learning theory of aggression. Journal of Communication, 28, $12-29$. 
Bandura, A., Barbaranelli, C., Caprara, G. V., \& Pastorelli, C. (1996). Mechanisms of moral disengagement in the exercise of moral agency. Journal of Personality and Social Psychology, 71, 364-374.

Bandura, A., Ross, D., \& Ross, S. (1961). Transmission of aggression through imitation of aggressive models. Journal of Abnormal and Social Psychology, 63, 575-582.

Bandura, A. Ross, D., \& Ross, S. (1963). Imitation of film-mediated aggressive models. Journal of Abnormal and Social Psychology, 66, 3-11.

Barongan, C., \& Nagayama Hall, G. C. (1995). The influence of misogynous rap music on sexual aggression against women. Psychology of Women Quarterly, 19(2), 195-207.

Berkowitz, L. (1962). Aggression: A social psychological analysis. New York: McGrawHill.

Berkowitz, L. (1969). The frustration-aggression hypothesis revisited. In L. Berkowitz (Ed.), Roots of aggression: A re-examination of the frustration-aggression hypothesis (pp. 1-28). New York: Artherton Press.

Berkowitz, L. (1984). Some effects of thoughts on anti- and prosocial influences of media events: A cognitive-neoassociation analysis. Psychological Bulletin, 95, 410-427.

Berkowitz, L. (1988). Frustrations, appraisals, and aversively stimulated aggression. Aggressive Behavior, 14, 3-10.

Berkowitz, L. (1989). Frustration-aggression hypothesis: Examination and reformulation. Psychological Bulletin, 106, 59-73. 
Berkowitz, L., \& LePage, A. (1967). Weapons as aggression-eliciting stimuli. Journal of Personality and Social Psychology, 7, 202-207.

Bettencourt, B. A., \& Kernahan, C. (1997). A meta-analysis of aggression in the presence of violent cues: Effects of gender differences and aversive provocation. Aggressive Behavior, 23(6), 447-456.

Bettencourt, B. A., Talley, A., Benjamin, A. J., \& Valentine, J. (2006). Personality and aggressive behavior under provoking and neutral conditions: A meta-analytic review. Psychological Bulletin, 132(5), 751-777.

Bower, G. (1981). Mood and memory. American Psychologist 36, 129-148.

Bushman, B. J., \& Anderson, C. A. (2001). Is it time to pull the plug on hostile versus instrumental aggression dichotomy? Psychological Review, 108, 273-279.

Center for Disease Control. (1991). Position papers from the Third National Injury Conference: Setting the National Agenda for Injury Control in the 1990s. Washington, DC: Department of Health and Human Services.

Chino69 (2002, September 17, 07:52:27pm). Tool - Cold and Ugly. Message posted to http://www.songmeanings.net/lyric.php?lid=2499

Collins, A. M., \& Loftus, E. F. (1975). A spreading activation theory of semantic processing. Psychological Review, 82, 407-428.

Cooper, J., \& Mackie, D. (1986). Video games and aggression in children. Journal of Applied Social Psychology, 16, 726-744. 
Day, K. D. (1980). The effect of music differing in excitatory potential and hedonic valence on provoked aggression. Dissertation Abstracts International, 41(1-A), 10.

Dill, J. C., \& Anderson, C. A. (1995). Effects of frustration justification on hostile aggression. Aggressive Behavior, 21, 359-369.

Dollard, J., Doob, L., Miller, N., Mowrer, O., \& Sears, R. (1939). Frustration and aggression. New Haven, CT: Yale University Press.

Donnerstein, E. (1980). Aggressive erotica and violence against women. Journal of Personality and Social Psychology, 39(2), 269-277.

Donnerstein, E., \& Berkowitz, L. (1981). Victim reactions in aggressive erotic films as a factor in violence against women. Journal of Personality and Social Psychology, 41(4), 710-724.

Doob, A. N., \& Kirshenbaum, H. M. (1973). The effects on arousal of frustration and aggressive films. Journal of Experimental Social Psychology, 9, 57-64.

DownedSystem (2002, February 4, 02:46:15am). Tool - Jerk Off. Message posted to http://www.songmeanings.net/lyric.php?lid=35181

Epstein, S., \& Taylor, S. P. (1967). Instigation to aggression as a function of degree of defeat and perceived aggressive intent of the opponent. Journal of Personality, 35(2), 265-289.

Feshbach, S. (1964). The function of aggression and the regulation of aggressive drive. Psychological Review, 71, 257-272. 
50 Cent. (2003a). Many Men. On Get Rich or Die Tryin' [CD]. Santa Monica, CA: Interscope Records.

50 Cent. (2003b). 21 Questions. On Get Rich or Die Tryin’ [CD]. Santa Monica, CA: Interscope Records.

Fox, W., \& Williams, J. (1974). Political orientation and music preference among college students. Public Opinion Quarterly, 38, 352-371.

Fraczek, A. (1974). Informational role of situation as a determinant of aggressive behavior. In J. deWit \& W. Hartup (Eds.), Determinants and origins of aggressive behavior. The Hague: Mouton.

Fritz, T., Jentschke, S., Gosselin, N., Sammler, D., Peretz, I., Turner, R., et al. (2009). Universal Recognition of Three Basic Emotions in Music. Current Biology, 19(7), 573-576.

Geen, R. G., \& Thomas, S. L. (1986). The immediate effects of media violence on behavior. Journal of Social Issues, 42(3), 7-28.

Gentile, D. A., Lynch, P. J., \& Linder, J. R. (2004). The effects of violent video game habits on adolescent hostility, aggressive behaviors, and school performance. Journal of Adolescence, 27(1), 5-22.

Grout, J. D., \& Palisca, C. V. (2001). A history of western music (6 ${ }^{\text {th }}$ ed.). New York: W.W. Norton \& Company.

Hansen, C. H., \& Hansen, R. D. (1988). How rock music videos can change what is seen when boy meets girl: Priming stereotypic appraisal of social interactions. Sex Roles, 19, 287-316. 
Hansen, C. H., \& Hansen, R. D. (1991). Schematic information processing of heavy metal lyrics. Communication Research, 18, 373-411.

Higgins, E. T., Rholes, W. S., \& Jones, C. R. (1977). Category accessibility and impression formation. Journal of Experimental Social Psychology, 13, 141-154.

Huesmann, L. R. (1986). Psychological processes promoting the relation between exposure to media violence and aggressive behavior by the viewer. Journal of Social Issues, 42, 125-139.

Huesmann, L. R. (1988). An information processing model for the development of aggression. Aggressive Behavior, 14, 13-24.

Huesmann, L. R. (1998). The role of social information processing and cognitive schemas in the acquisition and maintenance of habitual aggressive behavior. In R. G. Geen \& E. Donnerstein (Eds.), Human aggression: Theories, research, and implications for policy (pp. 73-109). New York: Academic Press.

Huesmann, L. R., Moise-Titus, J., Podolski, C. L., \& Eron, L. D. (2003). Longitudinal relations between children's exposure to TV violence and their aggressive and violent behavior in young adulthood: 1977-1992. Developmental Psychology, 39, 201-221.

Joint Statement on the impact of Entertainment Violence on Children: Congressional Public Health Summit (26 July 2000). Retrieved January 7, 2006 from http://www.aap.org/advocacy/releases/jstmtevc.htm. 
Josephson, W. L. (1987). Television violence and children's aggression: Testing the priming, social script, and disinhibition predictions. Journal of Personality and Social Psychology, 53(5), 882-890.

Lawrence, J. S. S., \& Joyner, D. J. (1991). The effects of sexually violent rock music on males' acceptance of violence against women. Psychology of Women Quarterly, 15, 49-63.

Leone, B., Szumski, B., Stalcup, B., Barbour, S., \& Dudley, W. (1999). Media violence: Opposing viewpoints. San Diego, CA: Greenhaven Press, Inc.

Malamuth, N. M., \& Check, V. P. (1981). The effects of mass media exposure on acceptance of violence against women: A field experiment. Journal of Research in Personality, 15, 436-446.

National Academy of Science. (1993). Understanding and preventing violence. Washington, DC: National Academy Press.

National Institute of Mental Health. (1982). Television and behavior: Ten years of scientific progress and implications for the eighties. Vol. 1. Summary Report. Washington, DC: U.S. Government Printing Office.

National television violence study (1996). Thousand Oaks, CA: Sage.

Paik, H., \& Comstock, G. (1994). The effects of television violence on antisocial behavior; a meta-analysis. Communication Research, 21, 516-547.

Pedersen, W., Gonzales, C., \& Miller, N. (2000). The moderating effect of trivial triggering provocation on displaced aggression. Journal of Personality and Social Psychology, 78(5), 913-927. 
Peterson, D. L, \& Pfost, K. S. (1989). Influence of rock videos on attitudes of violence against women. Psychological Reports, 64, 319-322.

Police, the. (1990a). Every Little Thing She Does is Magic. On Ghost in the Machine [CD]. Santa Monica, CA: A\&M Records.

Police, the. (1990b). Murder by Numbers. On Synchronicity [CD]. Santa Monica, CA: A\&M Records.

Rickard, N. S. (2004). Intense emotional responses to music: a test of the physiological arousal hypothesis. Psychology of Music, 32(4), 371-388.

Rustad, R. A., Small, J. E., Jobes, D. A., Safer, M .A., \& Peterson, R. J. (2003). The impact of rock videos and music with suicidal content on thoughts and attitudes about suicide. Suicide and Life-Threatening Behavior, 33, 120-131.

Sawyer, G. (2005). MP3 Gain (Version 1.2.5) [Computer software]. Retrieved January 18, 2005, from http://mp3gain.sourceforge.net/download.php

Schachter, S., \& Singer, J. (1962). Cognitive, social and physiological determinants of emotional state. Psychological Review 69, 379-399.

Schank, R. C. (1975). Conceptual information processing. New York: Elsevier.

Schank, R. C. (1982). Dynamic memory: A theory of reminding and learning in computers and people. Cambridge University Press.

Schank, R.C. (1986). Explanation patterns: Understanding mechanically and creatively. Hillsdale, NJ: Erlbaum.

Schank, R.C. \& Abelson, R. (1977). Scripts, plans, goals, and understanding. Hillsdale, NJ: Erlbaum. 
Sherif, M., Harvey, O. J., White, B. J., Hood, W. R., \& Sherif, C. W. (1961). Intergroup cooperation and competition: The robber's cave experiment. Norman, OK: University Book Exchange.

Sloboda, J. A. (1991). Music structure and emotional response: some empirical findings. Psychology of Music, 19, 110-120.

Smith, S. L., \& Boyson, A. R. (2002). Violence in music videos: Examining the prevalence and context of physical aggression. Journal of Communication, 52, 61-83.

Surgeon General's Scientific Advisory Committee on Television and Social Behavior. (1972). Television and growing up: The impact of televised violence. Washington, DC: U.S. Government Printing Office.

Taylor, S. (1967). Aggressive behavior and physiological arousal as a function of provocation and the tendency to inhibit aggression. Journal of Personality, 35(2), $297-310$

Tedeschi, J. T., \& Felson, R. B. (1994). Violence, aggression, \& coercive actions. Washington, DC: American Psychological Association.

Took, K. J. \& Weiss, D. S. (1994). The relationship between heavy metal and rap music and adolescent turmoil: Real or artifact? Adolescence, 29(115), 613-622.

Tool. (1992a). Cold and Ugly. On Opiate [CD]. New York: BMG Music. Tool. (1992b). Jerk-Off. On Opiate [CD]. New York: BMG Music. 
Trainor, L. J. \& Schmidt, L. A. (2003). Processing emotion induced by music. In Peretz, I.L. and Zatorre, R.J. (Eds.), The Cognitive Neuroscience of Music (pp. 310-324). Quebec, Canada: Oxford University Press.

Violence bill debated in Washington: Most panelists argued against legislation. (1990, February 5). Broadcasting, 118(6), 77-79.

Waite, B. M., Hillbrand, M., \& Foster, H. G. (1992). Reduction of aggressive behavior after removal of music television. Hospital and Community Psychiatry, 43, 173175.

Wanamaker, C. E. \& Reznikoff, M. (1989). Effects of aggressive and nonaggressive rock songs on projective and structured tests. The Journal of Psychology, 123(6), 561570.

Wester, S. R., Crown, C. L., Quatman, G. L., \& Heesacker, M. (1997). The influence of sexually violent rap music on attitudes of men with little prior exposure. Psychology of Women Quarterly, 21, 497-508.

Witvliet, C.V.O. (1997). The impact of music-prompted emotional valence and arousal on self-report, autonomic, facial emg, and startle responses across experimental contexts. Unpublished doctoral dissertation, Purdue University.

Zillmann, D. (1979). Hostility and aggression. Hillsdale, NJ: Erlbaum.

Zillmann, D. (1983). Arousal and aggression. In R. Geen \& E. Donnerstein (Eds.), Aggression: Theoretical and empirical reviews: Vol. 1, (p. 75-102). New York: Academic Press. 
Zillmann, D., \& Weaver, J. (1999). Effects of prolonged exposure to gratuitous media violence on provoked and unprovoked hostile behavior. Journal of Applied Social Psychology, 29(1), 145-165. 